\title{
Development of Cu-Exfoliated Graphite Nanoplatelets (xGnP) Metal Matrix Composite by Powder Metallurgy Route
}

\author{
Syed Nasimul Alam*, Lailesh Kumar, Nidhi Sharma \\ Metallurgical and Materials Engineering Department, National Institute of Technology Rourkela, Rourkela, \\ India \\ Email: syedn@nitrkl.ac.in, nasimulalam@yahoo.com
}

Received 29 July 2015; accepted 16 October 2015; published 19 October 2015

Copyright (C) 2015 by authors and Scientific Research Publishing Inc.

This work is licensed under the Creative Commons Attribution International License (CC BY). http://creativecommons.org/licenses/by/4.0/

(c) (7) Open Access

\section{Abstract}

In the present investigation the possibility of using exfoliated graphite nanoplatelets (xGnP) as reinforcement in order to enhance the mechanical properties of $\mathrm{Cu}$-based metal matrix composites is explored. Cu-based metal matrix composites reinforced with different amounts of $x G n P$ were fabricated by powder metallurgy route. The microstructure, sliding wear behaviour and mechanical properties of the $\mathrm{Cu}-\mathrm{xGn} P$ composites were investigated. $\mathrm{XGnP}$ has been synthesized from the graphite intercalation compounds (GIC) through rapid evaporation of the intercalant at an elevated temperature. The thermally exfoliated graphite was later sonicated for a period of $\mathbf{5} \mathrm{h}$ in acetone in order to achieve further exfoliation. The XGnP synthesized was characterized using SEM, HRTEM, X-ray diffraction, Raman spectroscopy and Fourier transform infrared spectroscopy. The $\mathrm{Cu}$ and $\mathrm{xGnP}$ powder mixtures were consolidated under a load of $565 \mathrm{MPa}$ followed by sintering at $850^{\circ} \mathrm{C}$ for $2 \mathrm{~h}$ in inert atmosphere. $\mathrm{Cu}-1,2,3$ and $5 \mathrm{wt} \% \mathrm{xGnP}$ composites were developed. Results of the wear test show that there is a significant improvement in the wear resistance of the composites up to addition of $2 \mathrm{wt} \%$ of $\mathrm{xGnP}$. Hardness, tensile strength and strain at failure of the various $\mathrm{Cu}$-xGnP composites also show improvement upto the addition of $2 \mathrm{wt} \% \mathrm{xGnP}$ beyond which there is a decrease in these properties. The density of the composites decreases with the addition of higher wt\% of $\mathrm{xGnP}$ although addition of higher wt\% of $\mathrm{xGnP}$ leads to higher sinterability and densification of the composites, resulting in higher relative density values. The nature of fracture in the pure $\mathrm{Cu}$ as well as the various $\mathrm{Cu}$-xGnP composites was found to be ductile. Nanoplatelets of graphite were found firmly embedded in the $\mathrm{Cu}$ matrix in case of $\mathrm{Cu}$-xGnP composites containing low wt\% of $\mathrm{xGnP}$.

\section{Keywords}

Powder Metallurgy, Exfoliated Graphite Nanoplatelets (xGnP), Cu-Based Metal Matrix Composite,

\footnotetext{
${ }^{*}$ Corresponding author.
} 


\section{Sliding Wear}

\section{Introduction}

Over the last several decades, there has been a considerable interest in the use of Cu-based metal matrix composites (MMCs). Cu has a wide range of excellent properties like high electrical conductivity $\left(5.98 \times 10^{6} \mathrm{~S} / \mathrm{m}\right)$, thermal conductivity $\left(401 \mathrm{~W} \cdot \mathrm{m}^{-1} \cdot \mathrm{K}^{-1}\right)$ and corrosion resistance. $\mathrm{Cu}$ has a melting point of $1083.4^{\circ} \mathrm{C}$ and its density is $8.96 \mathrm{gm} / \mathrm{cc}$. Its Young's modulus is $130 \mathrm{GPa}$. Its yield strength is $117 \mathrm{MPa}$ while its tensile strength is $210 \mathrm{MPa}$. The main drawback associated with $\mathrm{Cu}$ is its relatively low strength. For many applications pure $\mathrm{Cu}$ cannot be used because of its low strength. Therefore, improvement in the properties of $\mathrm{Cu}$ has become essential for its use in cutting-edge technological applications. $\mathrm{Cu}$ is used as a structural material for cooling as it has high thermal conductivity. In order to increase its high temperature properties, different reinforcements are being used. In recent years, graphene has attracted considerable research interest due to its unique properties. Graphene is a two-dimensional platelet made of carbon atoms. It is a one atom thick material and is a promising nanofiller that could improve the mechanical, electrical and thermal properties of the composites. Its excellent mechanical properties make it an ideal reinforcement for developing nanocomposites. It has a modulus of elasticity of $1 \mathrm{TPa}$ and a fracture strength is $125 \mathrm{GPa}$. The electrical resistivity of graphene is $10^{-6} \Omega \cdot \mathrm{cm}$ and its thermal conductivity is $\sim 3080-5300 \mathrm{~W} / \mathrm{m} \cdot \mathrm{K}$. One possible way of harnessing the extraordinary properties of graphene is by dispersing graphene in the polymer, metal or ceramic matrix [1]-[5]. Graphene nanoplatelets can be developed economically in large quantities which is why they are now considered as one of the most effective and economical reinforcements that could be used for developing metal matrix composites. Metal matrix composites are today extensively used in automobile and aerospace applications. Exfoliated graphite nanoplatelets (xGnP) could be an attractive reinforcement material for Cu-based metal matrix composites due to its high strength and elastic modulus. Unlike many other additives, graphite nanoplatelets can improve several mechanical properties of the matrix like stiffness, strength, surface hardness and wear resistance. The XGnP has platelet morphology and each platelet consists of several sheets of graphene. An important factor in producing $\mathrm{xGnP}$ is its low cost and the ease with which it can be produced. This makes the development of nanocomposites reinforced with $\mathrm{xGnP}$ very feasible. The unique combination of morphology and properties of the $\mathrm{xGnP}$ makes it a very versatile material that can act as a multifunctional additive for several potential applications [6]-[11].

This work explores the potential of using $\mathrm{xGnP}$ as a reinforcement in Cu-based metal matrix composites. $\mathrm{Cu}-\mathrm{xGnP}$ nanocomposites containing different wt\% of $\mathrm{xGnP}$ were fabricated using powder metallurgy route. Here an expandable graphite also known as the graphite intercalation compound (GIC) is developed first. It is prepared from natural flake graphite using acid intercalation in the presence of an oxidizing agent. Sulfuric acid $\left(\mathrm{H}_{2} \mathrm{SO}_{4}\right)$ has been used as the acid intercalant and hydrogen peroxide $\left(\mathrm{H}_{2} \mathrm{O}_{2}\right)$ has been used as an oxidizing agent. The GIC was later given a thermal treatment to produce exfoliated graphite. The expandable graphite prepared using the acid intercalation process can expand several times its original volume when heated to high temperatures [12]-[14]. Finally the thermally exfoliated graphite was sonicated in acetone in order to achieve further exfoliation. The $\mathrm{xGnP}$ developed was used as reinforcement in Cu-based metal matrix composites. In the present study $\mathrm{Cu}-1,2,3$ and $5 \mathrm{wt} \% \mathrm{xGnP}$ composites were developed. Effects of addition of $\mathrm{xGnP}$ on the morphology and the mechanical, tribological and fracture behavior of $\mathrm{Cu}-\mathrm{xGnP}$ composites have been investigated.

\section{Experimental}

Elemental Cu powder having purity $>99 \%$ and average particle size of $\sim 27 \mu \mathrm{m}$ and natural flake graphite (NFG) having 98\% purity and mesh size of $~ 60$ were procured form Loba Chemie. Sulfuric acid $\left(\mathrm{H}_{2} \mathrm{SO}_{4}\right)$ having $98 \%$ purity and hydrogen peroxide $\left(\mathrm{H}_{2} \mathrm{O}_{2}\right)$ having 30 vol\% concentration was obtained from Merck India. All reagents used were of analytical grade and had the highest commercially available purity. Expandable graphite was prepared at room temperature from the natural flake graphite by mixing $16 \mathrm{ml}$ of $\mathrm{H}_{2} \mathrm{SO}_{4}(98 \%)$ as an intercalant and $1.5 \mathrm{ml} \mathrm{H}_{2} \mathrm{O}_{2}(30 \%)$ as an oxidant with 6 gm of natural flake graphite under vigorous stirring. The mixture was placed for $1 \mathrm{~h} 30 \mathrm{~min}$ in a magnetic stirrer. The reaction mixture which was prepared after stirring was repeatedly washed and filtered in distilled water in order to achieve an aqueous mixture solution having $\mathrm{pH}$ in the 
range of $5-7$. Once the acidic impurities were removed and the prepared mixture was obtained through sedimentation it was then dried at $60^{\circ} \mathrm{C}$ for $30 \mathrm{~h}$ before further heat treatment. Finally the expandable graphite powder was subjected to a thermal shock in a muffle furnace at a temperature of $1000^{\circ} \mathrm{C}$ for $30 \mathrm{~s}$ in an air atmosphere resulting in the formation of thermally exfoliated graphite. The thermally exfoliated graphite was then dispersed in acetone in a magnetic stirrer for 30 minutes and thereafter it was dispersed in an ultrasonicator for 5 $\mathrm{h}$ in acetone in order to achieve further exfoliation. Figure 1 shows the schematic diagram illustrating the various steps that have been undertaken for the synthesis of the exfoliated graphite nanoplatelets (xGnP).

After proper mixing of the $\mathrm{Cu}$ and $\mathrm{xGnP}$ powders the $\mathrm{Cu}-\mathrm{xGnP}$ samples were developed by uniaxial cold compaction of the powder under a load of $565 \mathrm{MPa}$ followed by sintering at $850^{\circ} \mathrm{C}$ for $2 \mathrm{~h}$ in inert atmosphere. $\mathrm{Cu}-1,2,3,5 \mathrm{wt} \% \mathrm{xGnP}$ composites were developed. X-ray diffraction (XRD) of the various powders and composites were done in a Phillips PANalytical diffractometer using $\mathrm{Cu} \mathrm{K}_{\alpha}$ radiation $(\lambda=0.15406 \mathrm{~nm})$.

The microstructure of the composites were characterized using a JEOL JSM-6480LV scanning electron microscope (SEM) equipped with an Oxford Instrument INCAPentaFET-x3 energy dispersive X-ray spectroscopy (EDS) microanalysis system. A FEI NOVA NANO SEM 450(FEG) field-emission scanning electron microscope (FESEM) equipped with EDS (Bruker) was also used for analyzing the microstructure. A JEM-2100 JEOL HRTEM with a point to point resolution of $0.194 \mathrm{~nm}$ was used for analyzing the structure of graphite nanoplatelets. Atomic force microscopy (AFM) analysis was conducted by deposition of the graphite nanoplatelets on a mica substrate. A Park XE 70 AFM with a $100 \times 100 \mu \mathrm{m}$ XY-scanner and $10 \mu \mathrm{m}$ Z-scanner having a minimum lateral resolution of the order of $1 \mathrm{~nm}$ was used to analyze the samples using the non-contact mode. The non-contact tapping mode allows us nanometer resolution without disturbing the surface of the substrate. X-ray photoelectron spectroscopy (XPS) data was collected using a PHI 5000 VersaProbe II spectrometer with a monochromatized $\mathrm{Al} \mathrm{K}_{\alpha} \mathrm{X}$-ray source $(1486.6 \mathrm{eV})$. All multiplex scans used pass energy of $23.5 \mathrm{eV}$ with a scan step of $0.1 \mathrm{eV}$. The number of sweeps per peak was 10 and the scan range for binding energy was $0-1200 \mathrm{eV}$. Each XPS core level, i.e., C1s and O1s, considered in this study was analyzed using Shirley background subtraction and resolution into components via a curve fitting procedure using Lorentz peak fitting. A Shimadzu IR Prestige 21 Fourier transform infrared spectroscopy (FTIR) and a JobinYvon Horiba T64000 Raman spectrometer was used for spectroscopic analysis. The density of the samples was measured by Archimedes' principle. A Ducom ball-on-plate tribometer was used for the wear test of the various samples. Wear test was done under a load of $15 \mathrm{~N}$ using a diamond indenter. A Leeco Vickers microhardness tester was used to determine the hardness of the various samples. The tensile tests of the various samples were performed in an Instron 1195 computerized universal testing machine (UTM).

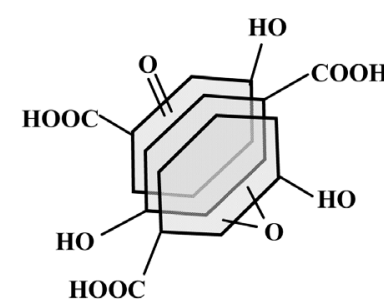

GIC

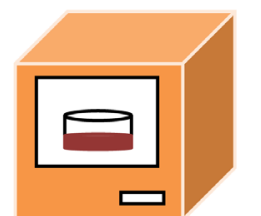

GIC was subjected to a thermal shock at $1000^{\circ} \mathrm{C}$ for $30 \mathrm{~s}$ in an air atmosphere

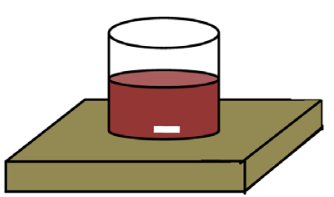

Dispersed in acetone in a magnetic stirrer for 30 minutes

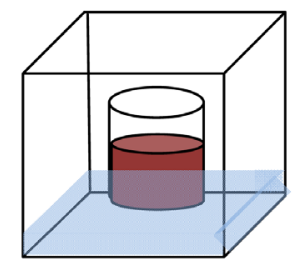

Dispersed in an ultrasonicator for $5 \mathrm{~h}$ in acetone in order to achieve further exfoliation

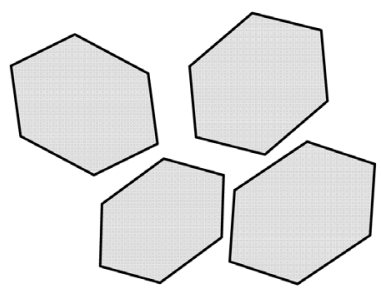

Exfoliated graphite nanoplatelets (xGnP)

Figure 1. Schematic diagram illustrating the various steps for the synthesis of exfoliated graphite nanoplatelets (xGnP). 


\section{Results and Discussion}

The X-ray diffraction spectra of the as-received natural flake graphite (NFG) and the exfoliated graphite nanoplatelets (xGnP) are shown in Figure 2(a) and Figure 2(b) respectively. From the X-ray diffraction of the asreceived NFG in Figure 2(a) it can be concluded that it is highly crystalline and has a very intense (002) peak at $2 \theta=26.42^{\circ}$ having a d-spacing of 3.3701 Á. Both the NFG and the $\mathrm{xGnP}$ showed (002) as the highest intensity peak at $26.42^{\circ}$. However, a comparison of the XRD plots in Figure 2(a) and Figure 2(b) shows a slight reduction in the intensity of the (002) peak in the case of $\mathrm{xGnP}$ as compared to that of the as-received NFG. In the case of $\mathrm{xGnP}$ the increased exfoliation achieved by the thermal exfoliation of the GIC followed by sonication in acetone in order to achieve further exfoliation has led to the reduction in the intensity of the (002) peak. This reduction in the peak intensity is associated with the characteristic interlayer spacing of the graphite. The distance between the graphite layers has increased due to the thermal exfoliation of the GIC and subsequent sonication in acetone. The graphite layers have separated and there is an apparent increase in the volume. The less intensity of the (002) peak in the case of XGnP clearly indicates that the as-received NFG has been exfoliated [15] [16].

Figure 3(a) and Figure 3(b) show the SEM images of the NFG. The SEM images show agglomerated particles of graphite. Figure 4(a) is the HRTEM image of the NFG. The SAD image in Figure 4(b) shows hexagonal patterns which indicate the six-fold symmetry of the carbon atoms arranged in the graphite plane. This confirms the highly crystalline nature of the NFG.

The exfoliation of intercalated graphite is a phase transition process which involves the vapourization of the

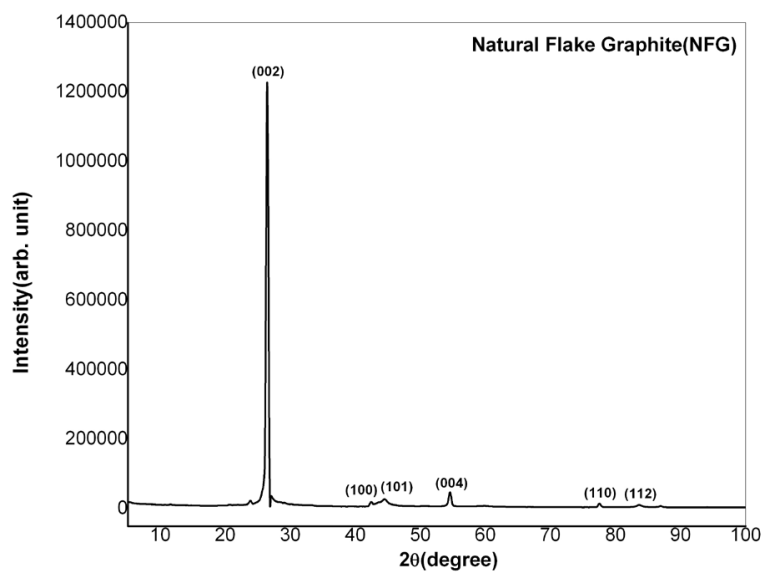

(a)

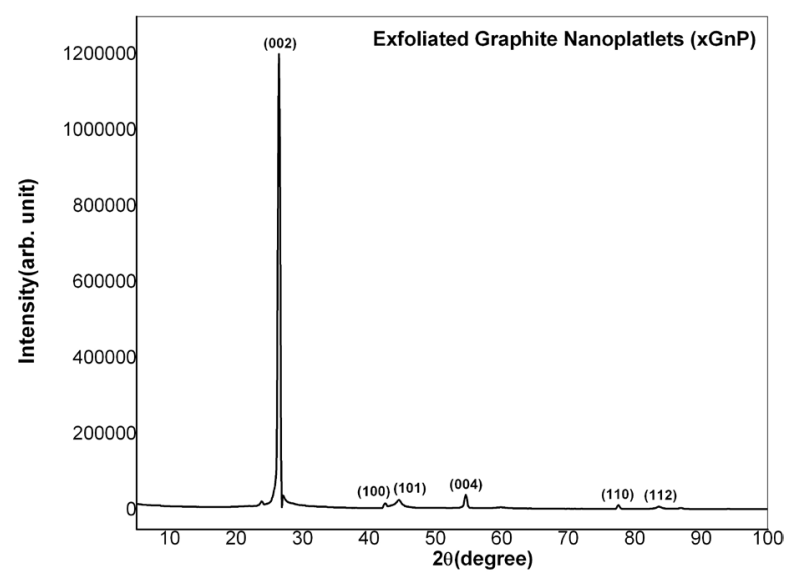

(b)

Figure 2. X-ray diffraction of (a) as-received NFG and (b) xGnP.

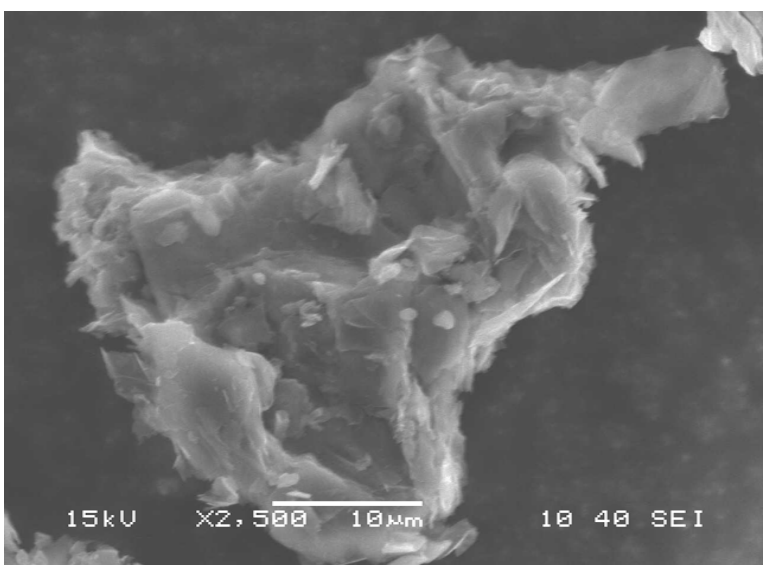

(a)

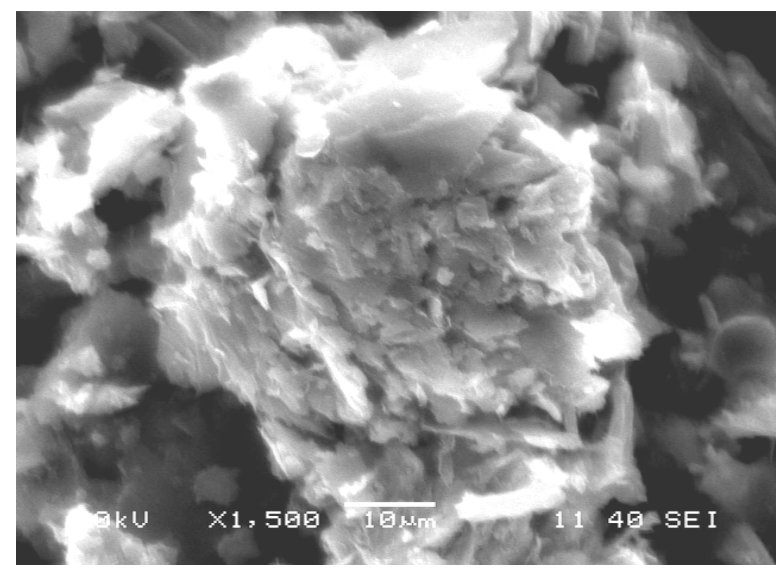

(b)

Figure 3. (a) \& (b) SEM of as-received natural flake graphite agglomerates. 


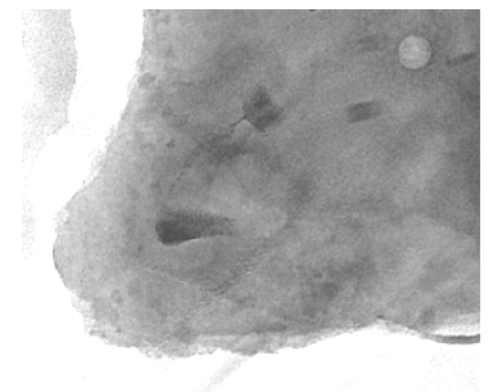

$100 \mathrm{~nm}$

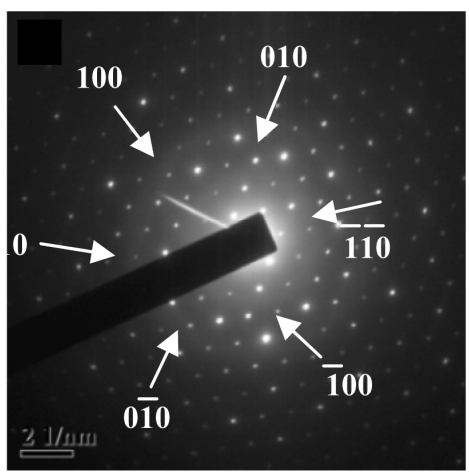

(b)

(a)

Figure 4. (a) HRTEM and (b) SAD image of as-received graphite.

intercalate in the graphite lattice. The $\mathrm{xGnP}$ formed by subjecting the GIC to a thermal shock at $1000^{\circ} \mathrm{C}$ for $30 \mathrm{~s}$ followed by sonication in acetone in order to achieve further exfoliation is found to consist of several sheets of graphene stacked together. The diameter of the platelets range from submicrons to more than $100 \mu \mathrm{m}$. The $\mathrm{xGnP}$ has been synthesized here from the GIC through rapid evaporation of the intercalant at an elevated temperature. The thermal exfoliation of the acid-intercalated graphite is known to produce few layer graphene very successfully [17] [18]. The product obtained is a very low density material having high temperature resistance. The compression of graphite nanoplatelets results in a material that has high lubricity and flexibility. The SEM micrographs in Figures 5(a)-(f) show the surface and interior structures of the $\mathrm{xGnP}$ synthesized by ultrasonication of the thermally exfoliated graphite. A large amount of inner pores between the flakes is visible in the SEM images. The $\mathrm{xGnP}$ has a lamellar structure. The SEM images show that the graphite nanoplatelets are not flat but have a flower petal like morphology. The ultrasonication method used for further exfoliation of the thermally exfoliated graphite has resulted in platelets having very high aspect ratio [19] [20].

The HRTEM micrographs of the XGnP synthesized from the NFG in Figures 6(a)-(d) show its morphology. The HRTEM images show that the xGnP are composed of several layers of graphene stacked together. These images suggest that the $\mathrm{xGnP}$ are highly transparent and have folded edges. In the HRTEM images in Figures 6(a)-(c) wrinkles could also be seen at the edges of the xGnP. A large number of broken graphite platelets could be seen in the HRTEM images. The $\mathrm{xGnP}$ have a large surface area with diameter of several microns. Due to their high surface area, the $\mathrm{xGnP}$ have a high tendency to coalesce into overlapped structures. Figure 6(d) is the HRTEM image at the rim of the graphite nanoplatelet. Figure 6(e) shows the SAD pattern of the xGnP along the [0 01 1] zone axis [21] [22].

The AFM analysis of the XGnP is shown in Figure 7(a). The AFM image shows regions where the change in elevation of as low as $3 \mathrm{~nm}$ could be detected. Considering that the thickness of the pristine graphene sheet is only $0.34 \mathrm{~nm}$ the number of graphene layers present in the platelet would be less than 10. However, the AFM analysis also shows areas where there is agglomeration of $\mathrm{xGnP}$. The XPS analysis of the $\mathrm{xGnP}$ in Figure 7(b) shows that the atomic \% of $\mathrm{C}$ is $96.2 \%$ and that of $\mathrm{O}$ as 3.8\% [23]-[25].

The synthesis of $\mathrm{xGnP}$ was further confirmed by using Raman spectroscopy. Using this technique it is possible to identify graphene from graphite and few-layers graphene. Raman spectroscopy is able to probe disorder in graphene through defect-activated peaks. The Raman spectra in Figure 8 consist of a set of distinct peaks. The $\mathrm{G}$ and $\mathrm{D}$ peaks appear around 1580 and $1350 \mathrm{~cm}^{-1}$ respectively. The $\mathrm{G}$ peak corresponds to the E2g phonon at the Brillouin zone center whereas the $\mathrm{D}$ peak is due to the breathing modes of the six-atom rings and requires a defect for its activation. The 2D peak (also called G0) is the second order of the D peak. This is a single peak in the case of single layer graphene, whereas it splits into four bands in bilayer graphene, reflecting the evolution of the electron band structure. Raman measurements were conducted on several spots of the NFG, thermally exfoliated graphite and $\mathrm{xGnP}$ obtained by ultrasonication of the thermally exfoliated graphite. The Raman spectra of the $\mathrm{xGnP}$ shows a sharp and strong $\mathrm{G}$ peak which is specific for $\mathrm{sp}_{2}$ carbon and reveals the high quality of the $\mathrm{xGnP}$. A sharp $\mathrm{G}$ peak and a weaker $\mathrm{D}$ peak indicate the presence of few layers of graphene in the $\mathrm{xGnP}$. The $\mathrm{D}$ peak is specific for disorders and defects which arise from the lattice deformation due to acid intercalation. The broad multi-band peaks around $2695 \mathrm{~cm}^{-1}$ (2D) are consistent with the multilayer feature of the $\mathrm{xGnP}$. 

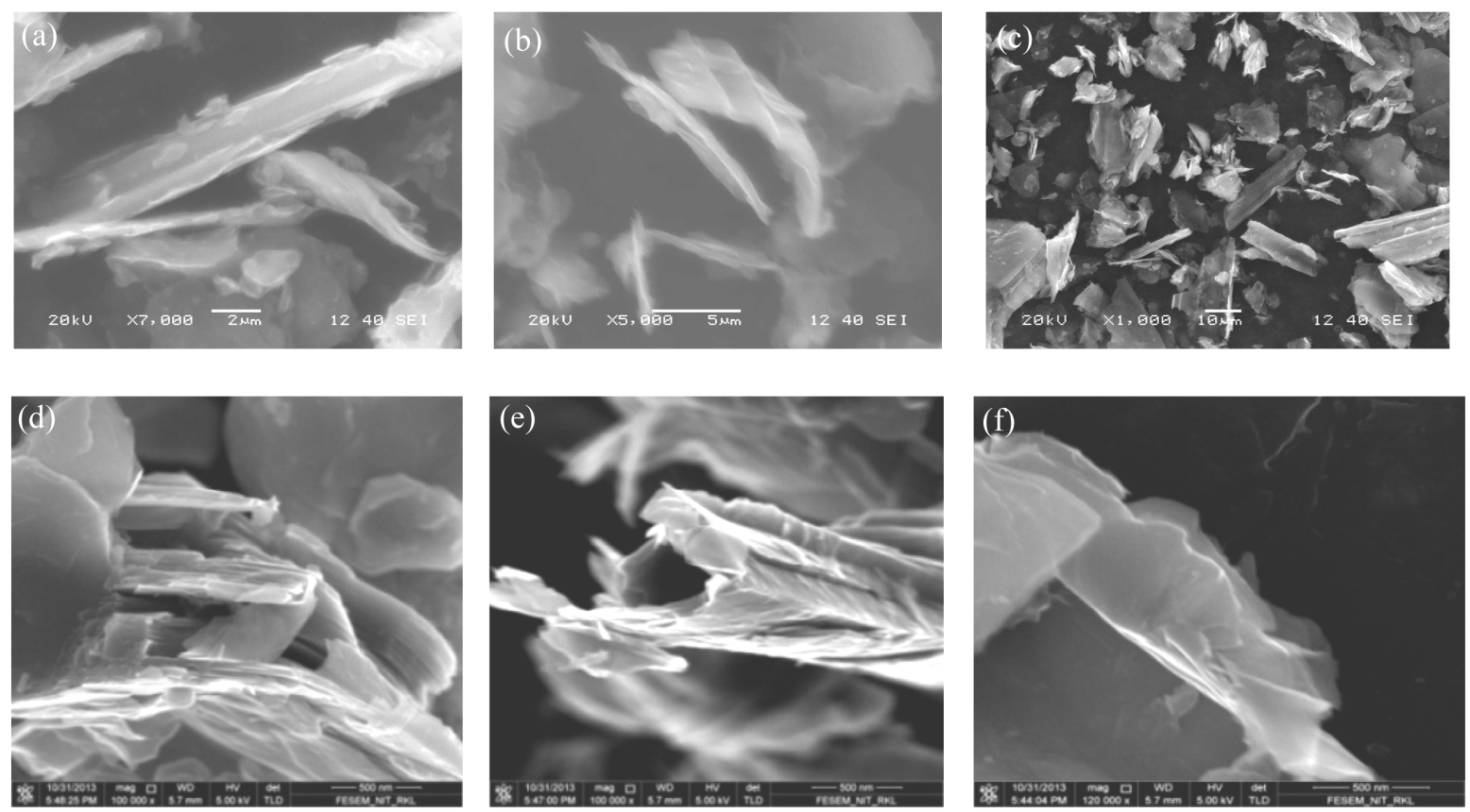

Figure 5. (a)-(f) SEM of xGnP synthesized by sonication of the thermally exfoliated graphite.
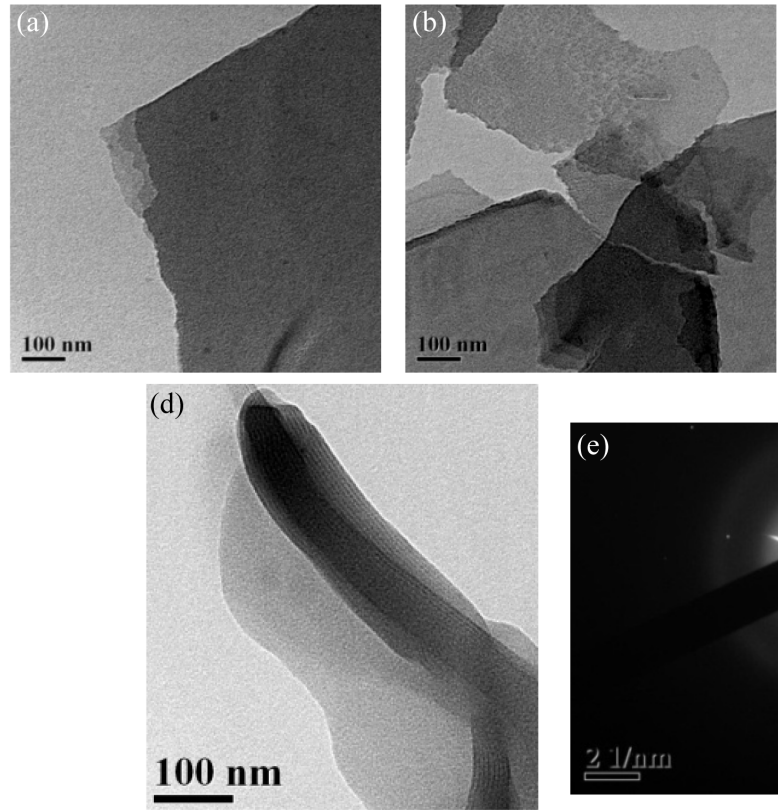
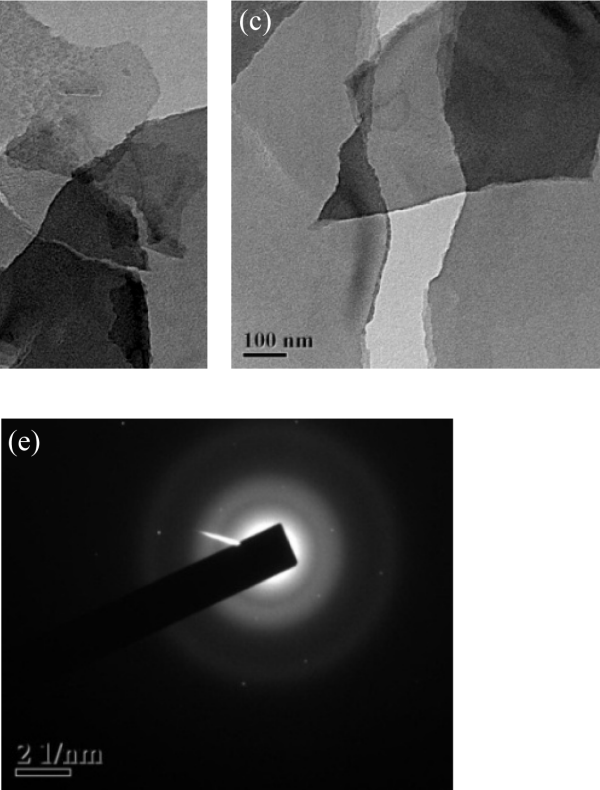

Figure 6. (a)-(d) HRTEM images and (e) SAD of xGnP.

Graphene is a planar sheet of sp2 bonded carbon atoms arranged in a hexagonal lattice. Disorder plays an important role on graphene properties. The formation of the GIC from the NFG led to the increased fictionalization and covalent bond formation. The intensity ratio of the $\mathrm{D}$ band at $1350 \mathrm{~cm}^{-1}$ to $\mathrm{G}$ band at $1580 \mathrm{~cm}^{-1}$ (ID/IG) can serve as a convenient measurement of the amount of defects in the graphitic materials. The ID/IG ratio for the NFG was found to be 0.10 whereas the ID/IG ratio increased slightly after the thermal exfoliation of the GIC at $1000^{\circ} \mathrm{C}$ for 30 seconds and was found to be 0.12 . The ID/IG ratio shows even further increase for the $\mathrm{xGnP}$ obtained by ultrasonication of the thermally exfoliated graphite and was found to be nearly equal to 0.29 . This ratio indicates that the crystal structure of $\mathrm{xGnP}$ has been preserved and is well ordered. However, the slight rise 


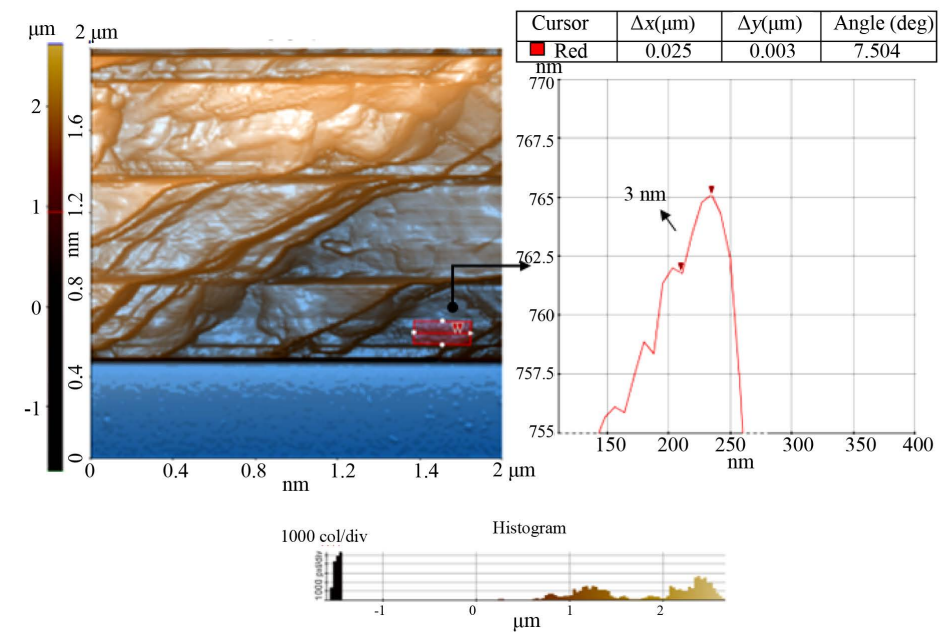

(a)

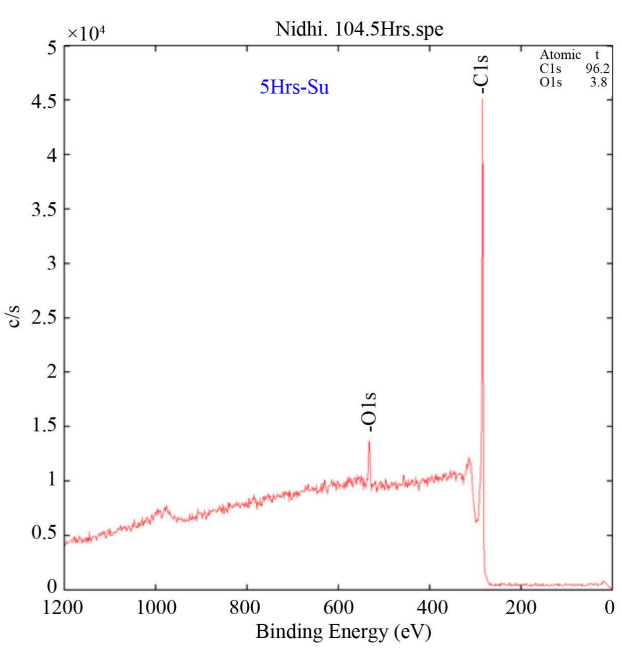

(b)

Figure 7. (a) AFM and (b) XPS analysis of xGnP.

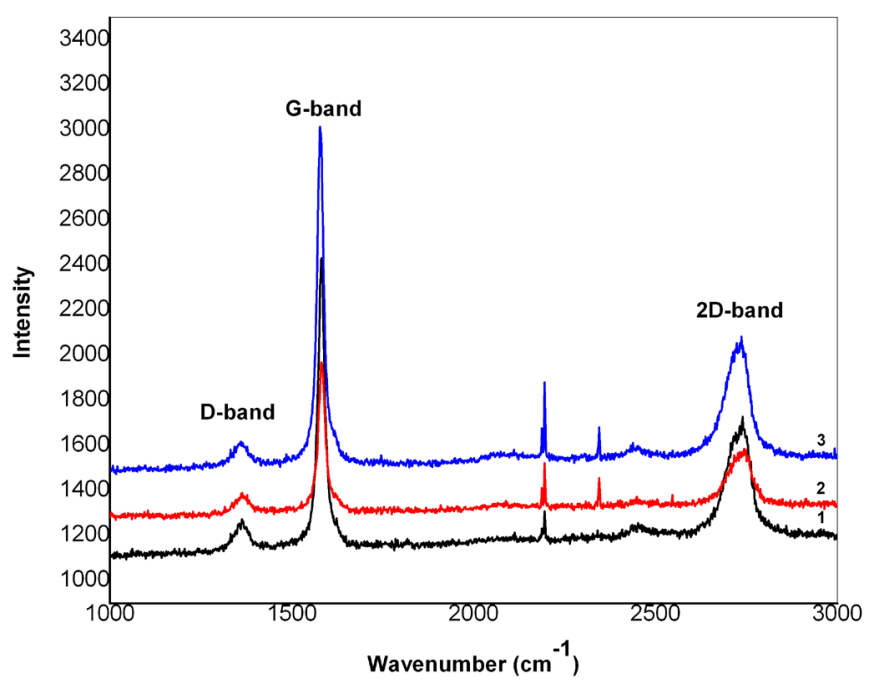

Figure 8. Raman spectra of (1) as-received natural flake graphite; (2) thermally exfoliated graphite; (3) xGnP.

in the value of ID/IG ratio can be explained by the destruction of the $\mathrm{C}=\mathrm{C}$ aromacity and the disappearance of the $s p^{2}$ carbon hexagonal structure. These results suggest that the exfoliation process was effective [26]-[28].

Figure 9 shows the FTIR spectrum for the xGnP recorded in the range of $400-4000 \mathrm{~cm}^{-1}$. A band of skeletal vibrations from the graphitic domains could be seen at around $1421 \mathrm{~cm}^{-1}$. At $1620 \mathrm{~cm}^{-1}$ skeletal vibrations from unoxidized graphitic domains were observed. Stretching vibrations from $\mathrm{C}=\mathrm{O}$ could be seen at around 1720 $\mathrm{cm}^{-1}$ due to the remaining of carboxyl groups and at $1060 \mathrm{~cm}^{-1} \mathrm{C}-\mathrm{O}$ stretching vibrations could be seen. The $\mathrm{C}=\mathrm{C}$ bending vibrations occur at frequencies below $500 \mathrm{~cm}^{-1}$. The peaks at around $2400 \mathrm{~cm}^{-1}$ correspond to the stretching and deformation vibrations of $\mathrm{CH}_{2}$. The peak at $2953.12 \mathrm{~cm}^{-1}$ corresponds to the $\mathrm{C}-\mathrm{H}$ group. The bands of O-H stretching vibrations are seen at $3400 \mathrm{~cm}^{-1}$ in the FTIR plot of the $\mathrm{xGnP}$. Thus FTIR spectroscopy provided convincing proof that the natural flake graphite was effectively transformed to $\mathrm{xGnP}$ by thermal shock [29] [30].

So far only few reports have been published on the use of graphite nanoplatelets to improve the mechanical properties of metal matrix composites. Here in our work the graphite nanoplatelets developed were subsequently used for the development of the $\mathrm{Cu}-\mathrm{xGnP}$ composites. The $\mathrm{Cu}$ and $\mathrm{xGnP}$ powder mixtures were blended and consolidated under a load of $565 \mathrm{MPa}$ followed by sintering at $850^{\circ} \mathrm{C}$ for $2 \mathrm{~h}$ in inert atmosphere. Cu-1, 2, 3 and 5 wt\% xGnP composites were developed. X-ray diffraction analysis was carried out for pure $\mathrm{Cu}$ and $\mathrm{Cu}-\mathrm{xGnP}$ 


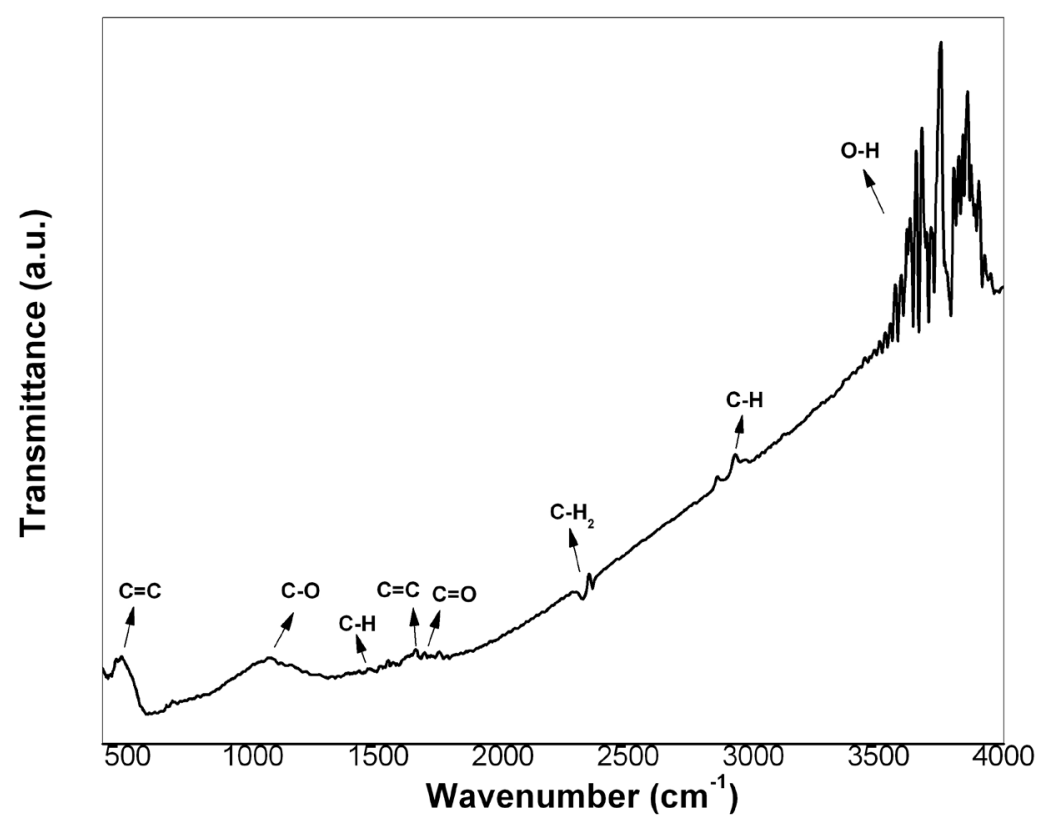

Figure 9. FTIR of xGnP.

composites in the range of $2 \theta=20^{\circ}-100^{\circ}$ as shown in Figure 10(a). Peaks corresponding to the (111), (200), (220) (311) and (222) planes of FCC Cu could be seen in the XRD plot. The XRD peak at $2 \theta=26.7^{\circ}$ corresponds to the (002) crystal plane of $\mathrm{xGnP}$. The (002) peak of $\mathrm{xGnP}$ could be seen clearly in the XRD plots of $\mathrm{Cu}-3$ and $5 \mathrm{wt} \% \mathrm{xGnP}$ composite. The intensity of the (002) peak of $\mathrm{xGnP}$ at $2 \theta=26.7^{\circ}$ increased with the increase of its content in the Cu-xGnP composite as seen in Figure 10(b). Besides this few peaks corresponding to $\mathrm{Cu}_{2} \mathrm{O}$ could also be seen in the XRD plots of the various $\mathrm{Cu}-\mathrm{XGnP}$ composites. This is due to the oxidation of $\mathrm{Cu}$ to $\mathrm{Cu}_{2} \mathrm{O}$. XRD analysis also indicated that there is no carbide formation in the composites. The binary phase diagram of the $\mathrm{Cu}-\mathrm{C}$ system in Figure 10(c) also shows the absence of any compounds between $\mathrm{Cu}$ and $\mathrm{C}$ [31][33].

The various samples of $\mathrm{Cu}-\mathrm{xGnP}$ composites were observed under an optical microscope. The optical micrograph of Cu-1 and 2 wt\% xGnP composite in Figure 11(b) and Figure 11(c) respectively clearly show that there is a homogeneous distribution of fine $\mathrm{xGnP}$ throughout the $\mathrm{Cu}$ matrix. The $\mathrm{xGnP}$ is evenly distributed throughout the $\mathrm{Cu}$ matrix and there is no evidence of agglomeration in these samples. Addition of more than $2 \mathrm{wt} \%$ of $\mathrm{xGnP}$ in the $\mathrm{Cu}$ matrix leads to the agglomeration of $\mathrm{xGnP}$ in the $\mathrm{Cu}$ matrix. The optical micrograph of $\mathrm{Cu}-3 \mathrm{wt} \%$ $\mathrm{xGnP}$ nanocomposite shown in Figure 11(d) shows small agglomerates of $\mathrm{xGnP}$ in the range of $\sim 35 \mu \mathrm{m}$. Large agglomerates of $\mathrm{xGnP}$ could be clearly seen in the case of $\mathrm{Cu}-5 \mathrm{wt} \% \mathrm{xGnP}$ nanocomposites. The optical micrograph of Cu-5 wt\% xGnP composite in Figure 11(e) shows agglomerates of xGnP having size of $\sim 282 \mu \mathrm{m}$.

Additional characterization by SEM along with EDS of the samples were done for finding out the distribution of $\mathrm{xGnP}$ in the various composites. Similar results as seen in the optical micrographs could also be seen in the SEM images of the various $\mathrm{Cu}-\mathrm{xGnP}$ composites. $\mathrm{Cu}-1 \mathrm{wt} \% \mathrm{xGnP}$ nanocomposite shows a very uniform distribution of $x \mathrm{GnP}$ in the $\mathrm{Cu}$ matrix in Figure 12(a). The SEM image in Figure 12(b) of Cu-3 wt\% xGnP shows slightly larger agglomerates of $\mathrm{xGnP}$ in the $\mathrm{Cu}$ matrix suggesting that addition of higher wt\% of $\mathrm{xGnP}$ could possibly lead to agglomeration of the xGnP. The SEM image of Cu-5 wt\% xGnP in Figure 12(c) clearly shows large agglomerates of $\mathrm{xGnP}$ in the $\mathrm{Cu}$ matrix. The EDS analysis of the dark region in the $\mathrm{Cu}-5 \mathrm{wt} \% \mathrm{xGnP}$ composite sample in Figure 12(c) shows that the large dark agglomerates are 100\% C confirming that these regions are agglomerates of $\mathrm{xGnP}$. The performance of nanocomposites depends on the dispersion of the nanofillers in the matrix. HRTEM is a widely used technique to evaluate the dispersion of the nanofillers in a metal matrix. HRTEM micrographs were collected to gain better understanding of the $\mathrm{xGnP}$ dispersion in the $\mathrm{Cu}$ matrix. The HRTEM images of the Cu-2 wt\% xGnP nanocomposites in Figures 12(d)-(f) reveal that the xGnPs maintained their inherent layered structure even after being sintered, although a few agglomerations of $\mathrm{xGnP}$ could also be observed. No gaps were found at the interface of the $\mathrm{xGnP}$ and the $\mathrm{Cu}$ matrix. The image in Figure 12(g) is the 


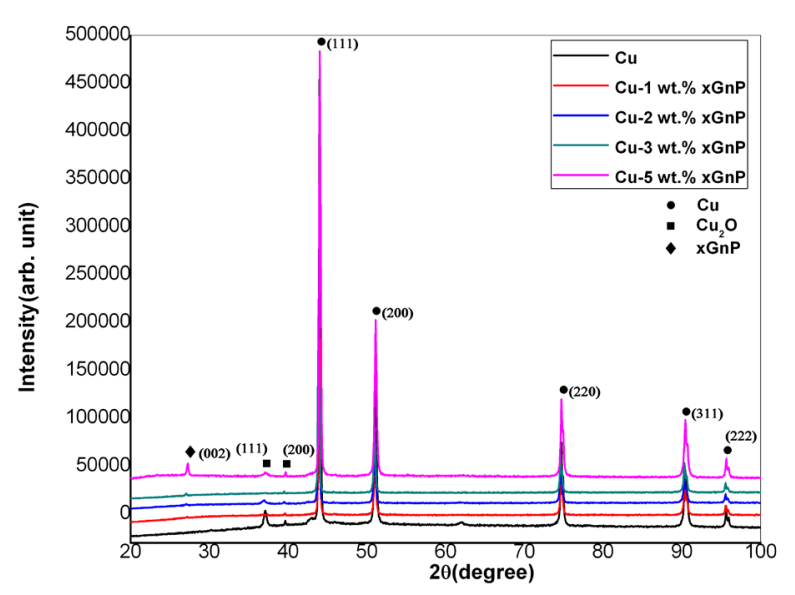

(a)

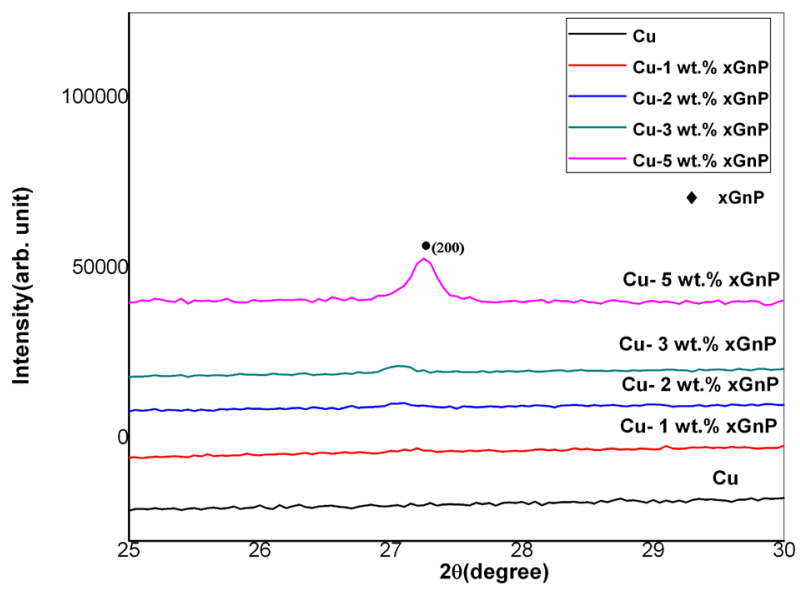

(b)

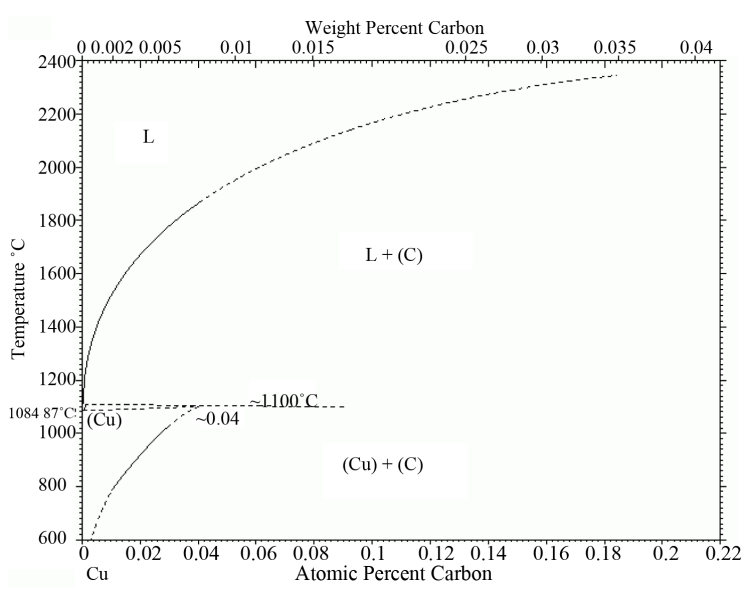

(c)

Figure 10. (a) X-ray diffraction of $\mathrm{Cu}$ and various $\mathrm{Cu}-\mathrm{xGnP}$ composites; (b) X-ray diffraction plot of $\mathrm{Cu}-\mathrm{xGnP}$ composites in the range of $2 \theta=25^{\circ}-30^{\circ}$; (c) Binary phase diagram of Cu-C system [34].

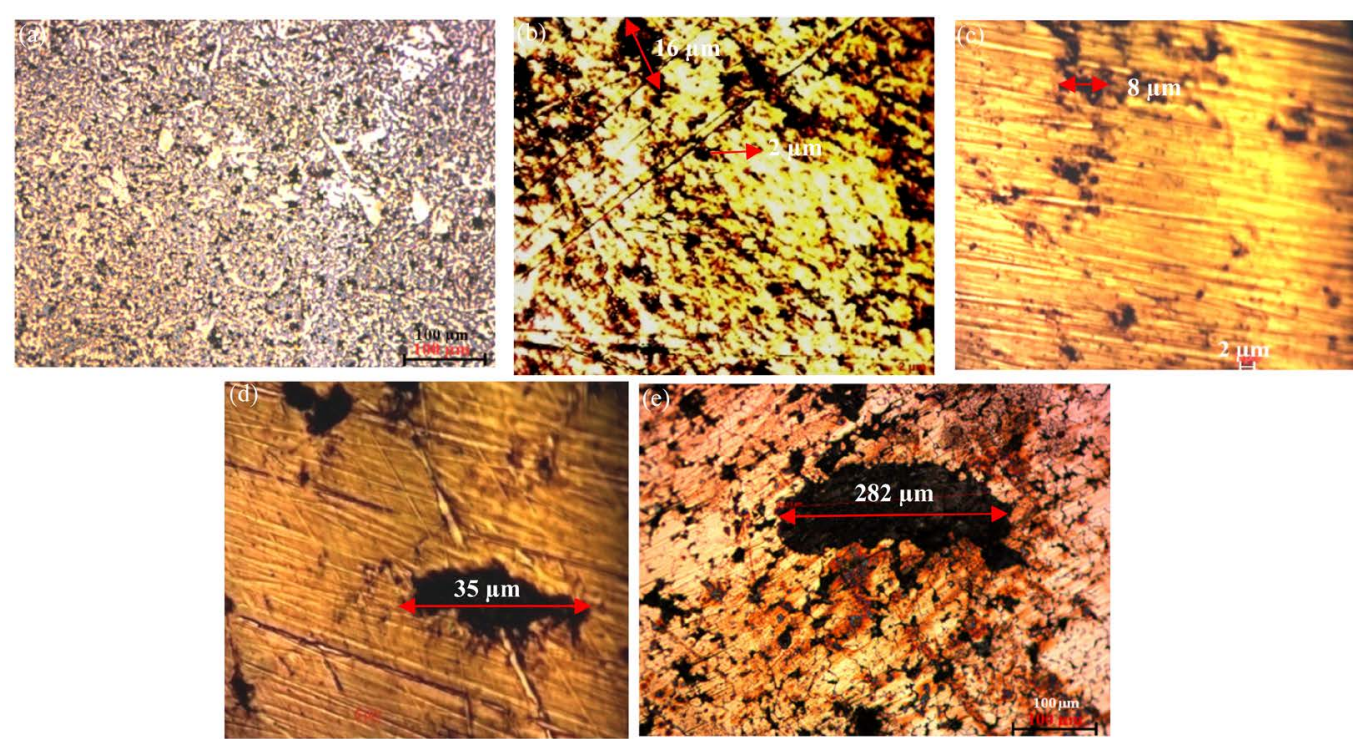

Figure 11. Optical micrograph of (a) Cu; (b) Cu-1 wt\% xGnP; (c) Cu-2 wt\% xGnP; (d) Cu-3 wt\% xGnP; and (e) Cu-5 wt\% xGnP nanocomposites. 


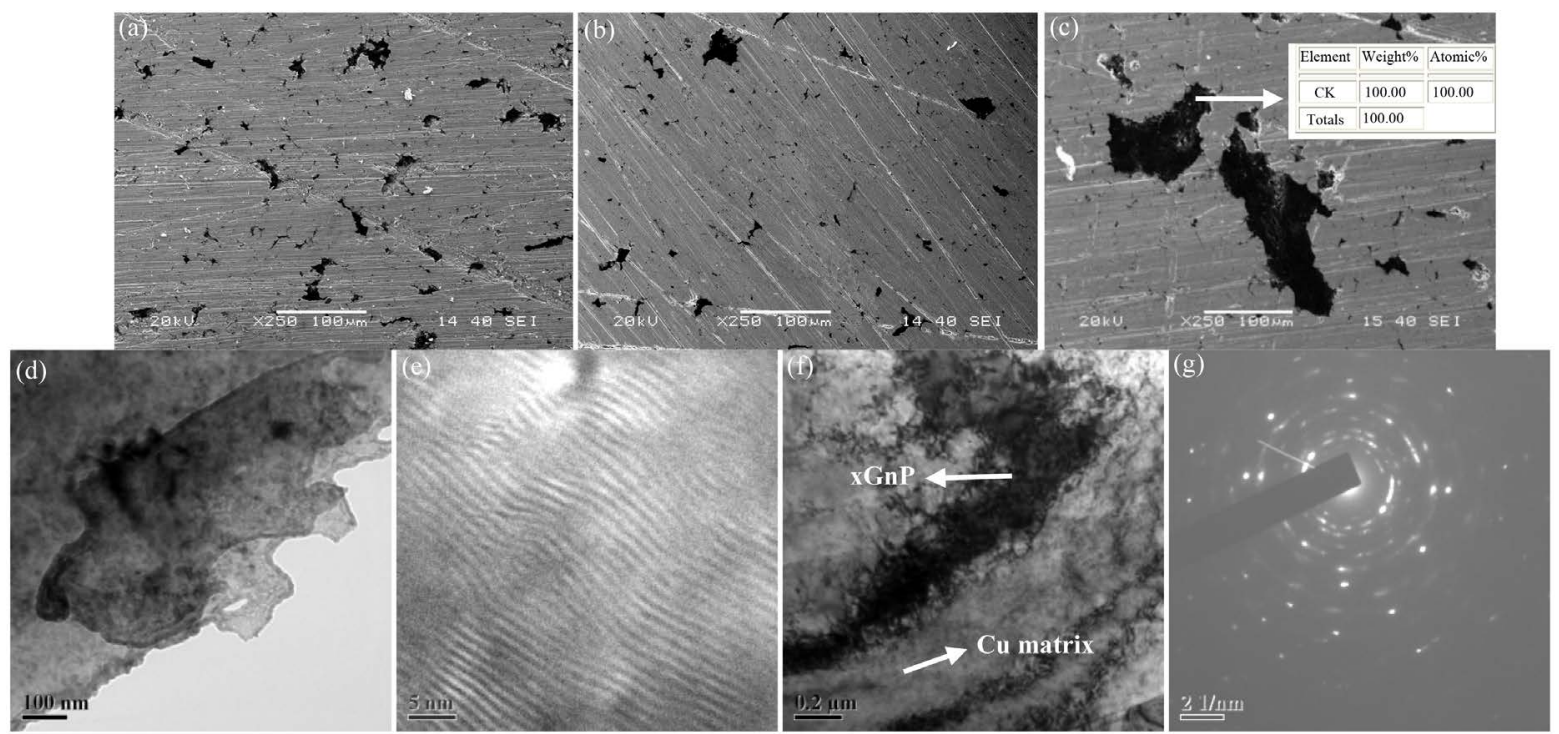

Figure 12. SEM images of (a) Cu-1 wt\% xGnP; (b) $\mathrm{Cu}-3$ wt\% xGnP; and (c) $\mathrm{Cu}-5 \mathrm{wt} \% \mathrm{xGnP}$ nanocomposites; (d)-(f) HRTEM images and (g) SAD pattern of $\mathrm{Cu}-2 \mathrm{wt} \% \mathrm{xGnP}$ nanocomposite.

SAD pattern from the sample. The SEM and HRTEM analysis suggests that there is a close contact between the $\mathrm{Cu}$ matrix and the $\mathrm{xGnP}$ in the $\mathrm{Cu}-\mathrm{xGnP}$ composites which contributes in enhancing the mechanical properties of the composites. Graphite nanoplatelets could be found in the grain boundary junctions [4] [35]-[37].

The theoretical density of the various $\mathrm{Cu}-\mathrm{xGnP}$ composites was calculated using the rule of mixtures where the density of $\mathrm{xGnP}$ was $2.1 \mathrm{gm} / \mathrm{cc}$ and the density of $\mathrm{Cu}$ was $8.9 \mathrm{gm} / \mathrm{cc}$. It is clear from the plot of the theoreti$\mathrm{cal}$ and experimental density in Figure 13(a) that with the increase in content of $\mathrm{xGnP}$ in the $\mathrm{Cu}-\mathrm{xGnP}$ composites there is a reduction in both the theoretical and experimental density of the $\mathrm{Cu}-\mathrm{xGnP}$ composites. As the density of $\mathrm{xGnP}$ is lower than the density of pure $\mathrm{Cu}$, the addition of $\mathrm{xGnP}$ in the $\mathrm{Cu}-\mathrm{xGnP}$ composites leads to a lower density of the composites as compared to pure $\mathrm{Cu}$. However, the relative density values of all the $\mathrm{Cu}$ $\mathrm{xGnP}$ composites shown in Figure 13(b) are higher than that of the sintered pure $\mathrm{Cu}$ sample. This is due to the better sinterability and higher densification the $\mathrm{Cu}-\mathrm{xGnP}$ composites due to the addition of nanosized $\mathrm{xGnP}$. The $\mathrm{xGnP}$ having nanometric dimension is capable of filling the pores in the $\mathrm{Cu}$ matrix more effectively leading to better densification.

Vickers microhardness was used to determine the hardness of both pure $\mathrm{Cu}$ and $\mathrm{Cu}-\mathrm{xGnP}$ composites. The hardness values were measured on the polished surface of the various composites. It can be seen from the plot in Figure 14 that the hardness of the $\mathrm{Cu}-\mathrm{xGnP}$ composite is higher than that of pure $\mathrm{Cu}$ when the $\mathrm{xGnP}$ content in the composites is upto $2 \mathrm{wt} \%$. Increased hardness of composite can be attributed to the uniform distribution of the $\mathrm{xGnP}$ in the composite. However, beyond $2 \mathrm{wt} \%$ of $\mathrm{xGnP}$ the hardness of the composite decreases possibly due to the agglomeration of the $\mathrm{xGnP}$ in the $\mathrm{Cu}$ matrix. The agglomeration of $\mathrm{xGnP}$ in the $\mathrm{Cu}-\mathrm{xGnP}$ composites was evident from the optical and SEM images of the $\mathrm{Cu}-\mathrm{xGnP}$ composites containing more than $2 \mathrm{wt} \% \mathrm{xGnP}$ in Figure 11(d) and Figure 11(e) and Figure 12(b) and Figure 12(c) respectively [38]-[40].

In order to find out the effect of the addition of $\mathrm{xGnPs}$ on the tensile properties of the $\mathrm{Cu}-\mathrm{xGnP}$ composites the tensile tests of the various composites were done. Figure 15(a) and Figure 15(b) show the variation of tensile strength and strain to failure with the addition of $\mathrm{xGnP}$ in the various $\mathrm{Cu}-\mathrm{xGnP}$ composites respectively. It is evident from the plot in Figure 15(a) that upto the addition of $2 \mathrm{wt} \% \mathrm{xGnP}$ in the $\mathrm{Cu}-\mathrm{xGnP}$ composites the tensile strength of the $\mathrm{Cu}-\mathrm{xGnP}$ composites increases. Addition of $\mathrm{xGnP}$ beyond $2 \mathrm{wt} \%$ leads to the decrease of the tensile strength of the composite. A similar effect of the $\mathrm{xGnP}$ on the strain to failure of the $\mathrm{Cu}-\mathrm{xGnP}$ composites was also observed. The plot in Figure 15(b) clearly indicates that upto the addition of $2 \mathrm{wt} \% \mathrm{xGnP}$ in the $\mathrm{Cu}-\mathrm{xGnP}$ composites the strain to failure of the $\mathrm{Cu}-\mathrm{xGnP}$ composites increases. However, addition of $\mathrm{xGnP}$ beyond $2 \mathrm{wt} \%$ leads to the decrease of the strain to failure of the composite. This is possibly due to the agglomeration of $\mathrm{xGnP}$. It is found that agglomeration of $\mathrm{xGnP}$ has led to a decrease in the hardness as well as the tensile strength of the $\mathrm{Cu}-\mathrm{xGnP}$ composites when $\mathrm{xGnP}$ content in the composites was more that $2 \mathrm{wt} \%$. The high intrinsic mechanical strength of the graphite nanoplatelets enabled them to block dislocation motion and 


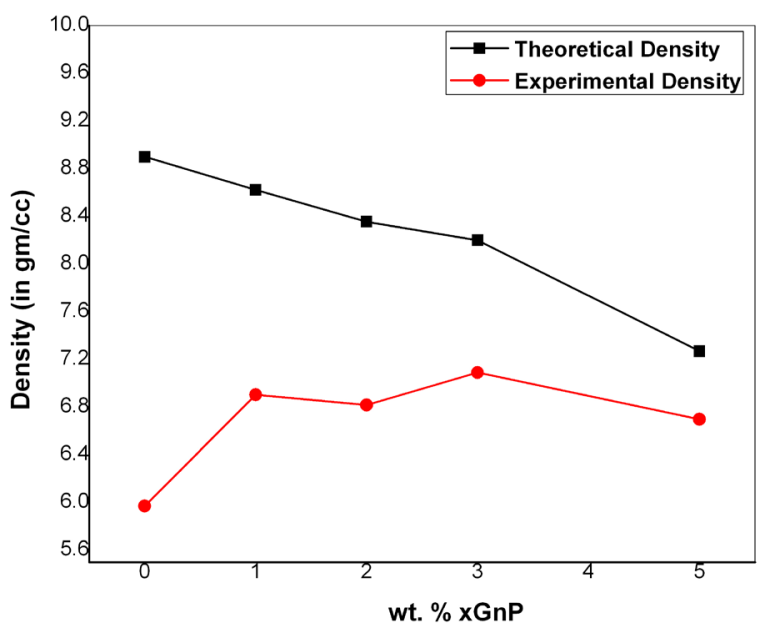

(a)

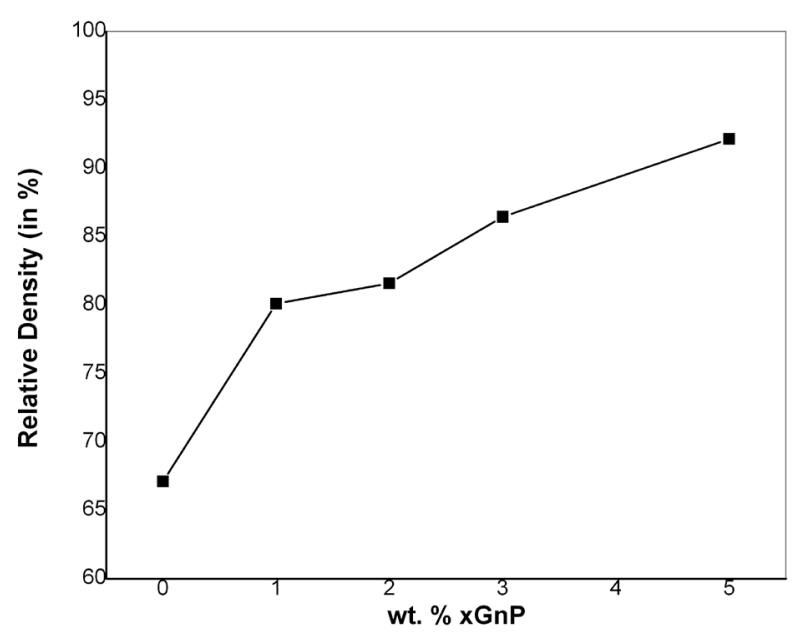

(b)

Figure 13. (a) Variation of theoretical density and experimental density with variation of $x G n P$ content in the $\mathrm{Cu}-\mathrm{xGnP}$ composites; (b) Variation of relative density with variation of $\mathrm{xGnP}$ content in the $\mathrm{Cu}-\mathrm{xGnP}$ composites.

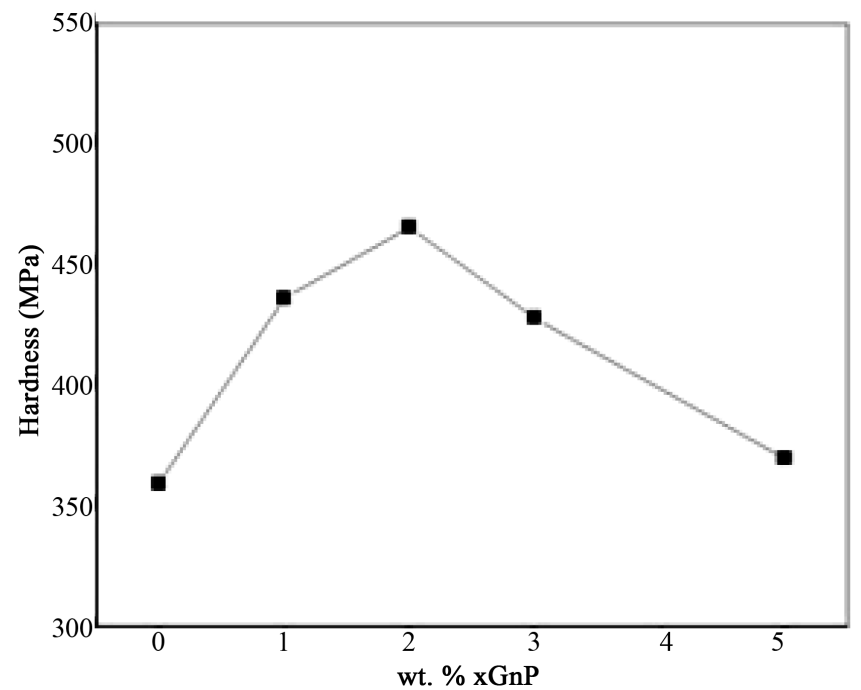

Figure 14. Variation of hardness with variation of $\mathrm{xGnP}$ content in the $\mathrm{Cu}-\mathrm{xGnP}$ composites.

prevent the rupture and shearing of the $\mathrm{Cu}$ matrix. The graphite nanoplatelets restricted the propagation of the dislocations across the interface. This results in high strength of the composites. The strengthening that has been gained in the $\mathrm{Cu}-\mathrm{xGnP}$ composites through the homogeneous dispersion of the graphite nanoplatelets in the $\mathrm{Cu}$ matrix can be attributed to the Orowan strengthening mechanism [32] [41].

Cu-based metal matrix composites are used in a wide range of applications like heat exchangers, structural parts, electrical connectors, in contacts like brushes, frictional parts of machines like bearings and bushings etc. Relative motion between the surfaces results in friction, as well as progressive loss of the material. This is why the study of the wear properties of the $\mathrm{Cu}-\mathrm{xGnP}$ composites is a very important. In order to understand how the $\mathrm{Cu}-\mathrm{xGnP}$ composites behave while in contact with a hard material the wear properties of the $\mathrm{Cu}-\mathrm{xGnP}$ composites were studied in unlubricated ball-on-plate experiments using a tribometer. The samples were in the form of polished disks having $15 \mathrm{~mm}$ diameter and $3 \mathrm{~mm}$ thickness. The specimens were tested normal to the major surface with a load of $15 \mathrm{~N}$ using a diamond indenter.

Figure 16 shows the variation of wear depth with time for pure $\mathrm{Cu}$ and $\mathrm{Cu}-1,2,3$ and 5 wt $\%$ xGnP. We observe an increase in wear resistance of the $\mathrm{Cu}-\mathrm{xGnP}$ composite upto the addition of $2 \mathrm{wt} \% \mathrm{xGnP}$. The homogeneous distribution of $\mathrm{xGnP}$ in the $\mathrm{Cu}$ matrix leads to a lower coefficient of friction of the Cu-xGnP composites. 


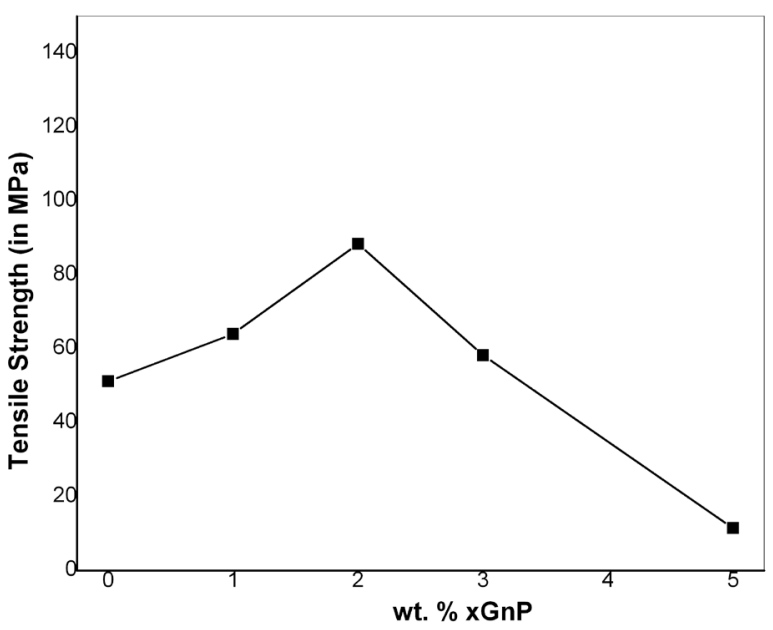

(a)

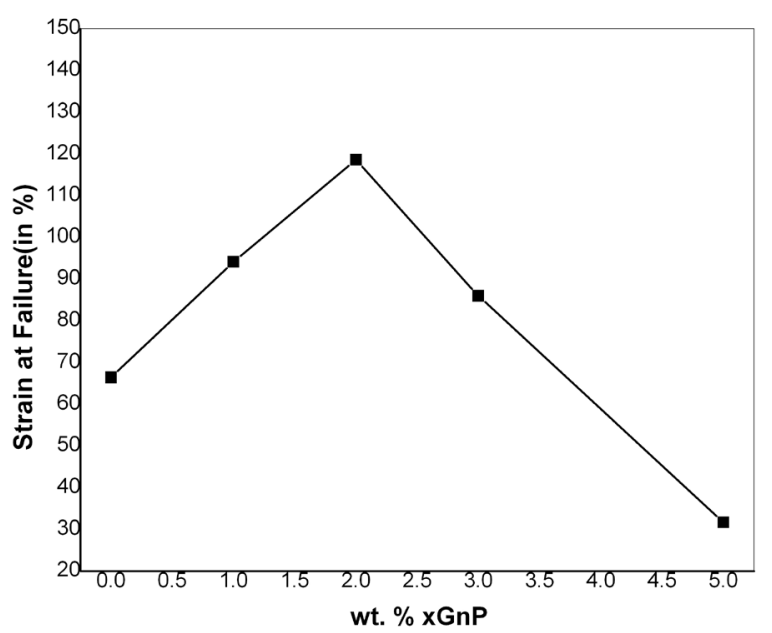

(b)

Figure 15. Variation of (a) tensile strength and (b) strain to failure with addition of $\mathrm{xGnP}$ in various $\mathrm{Cu}-\mathrm{xGnP}$ composites.

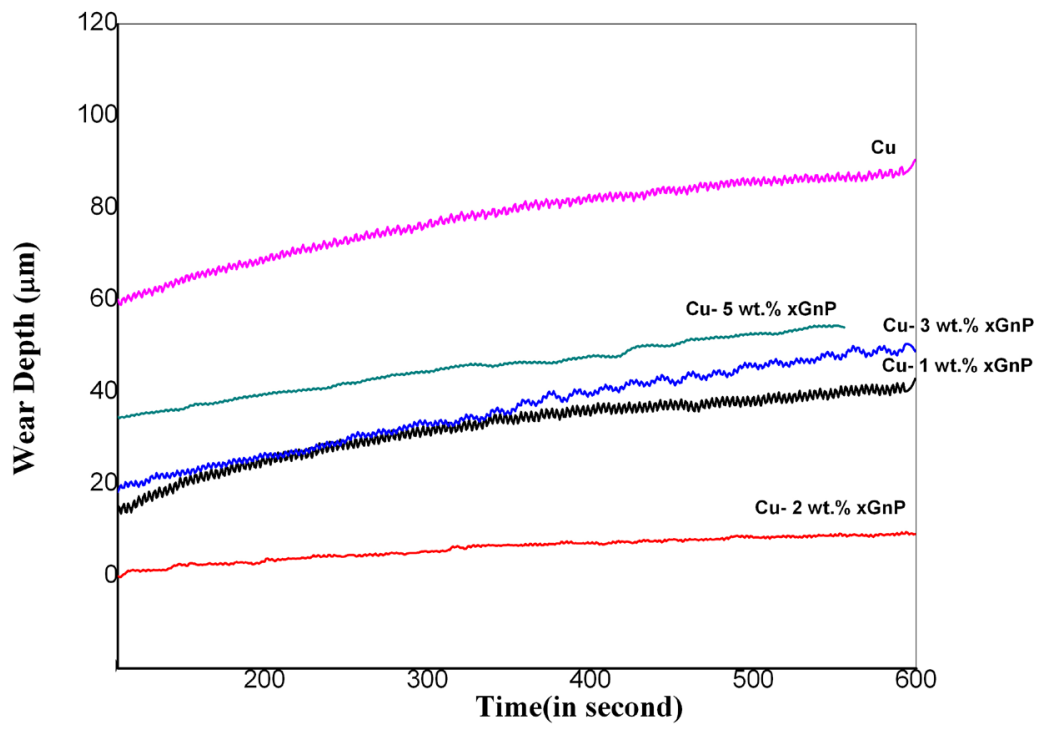

Figure 16. Variation of wear depth with time for pure $\mathrm{Cu}$ and $\mathrm{Cu}-1,2,3$ and $5 \mathrm{wt} \% \mathrm{xGnP}$ composites.

During sliding, the friction between the diamond indenter and the $\mathrm{Cu}-\mathrm{xGnP}$ composites is less due to the multilayer structure of $\mathrm{xGnP}$ which provides a lubricating effect to the $\mathrm{Cu}$ matrix, resulting in a reduced coefficient of friction. However, Cu-3 and 5 wt\% xGnP composites exhibit poor wear resistance leading to an increase in wear depth. The reduction in the wear resistance of the $\mathrm{Cu}-\mathrm{xGnP}$ composites when the content of xGnP in the composites is beyond $2 \mathrm{wt} \%$ is possibly due to the effect of agglomeration of $\mathrm{xGnP}$ in the composites.

Figures 17(a)-(e) show the SEM images of the wear track of pure $\mathrm{Cu}$ and $\mathrm{Cu}-1,2$, 3 and $5 \mathrm{wt} \% \mathrm{xGnP}$ composites. The width of the wear track is minimum in the case of $\mathrm{Cu}-2 \mathrm{wt} \% \mathrm{xGnP}$ and is found to be around 520 $\mu \mathrm{m}$. The smallest amount of wear debris is also observed in the case of Cu- $2 \mathrm{wt} \% \mathrm{xGnP}$ composite and the surface of the wear track of the composite is also much smoother in comparison to other samples. The increase in the wear resistance of $\mathrm{Cu}-2 \mathrm{wt} \% \mathrm{xGnP}$ nanocomposite is due to the formation of an interconnected network of $x \mathrm{GnP}$ inside the $\mathrm{Cu}$ matrix. The interconnected network of $\mathrm{xGnP}$ gives a lubricating effect that helps in reducing the removal of material from the $\mathrm{Cu}$ matrix. The two-dimensional geometry of the $\mathrm{xGnP}$ forms a lubricating layer on the surface of $\mathrm{Cu}$ limiting the damage during the wear test. The increased wear resistance of the $\mathrm{Cu}-\mathrm{xGnP}$ composites is also linked to its improved mechanical properties. Addition of xGnP beyond 2 wt\% increased the width of the wear track significantly. This is possibly due to the agglomeration of $x G n P$ when a 

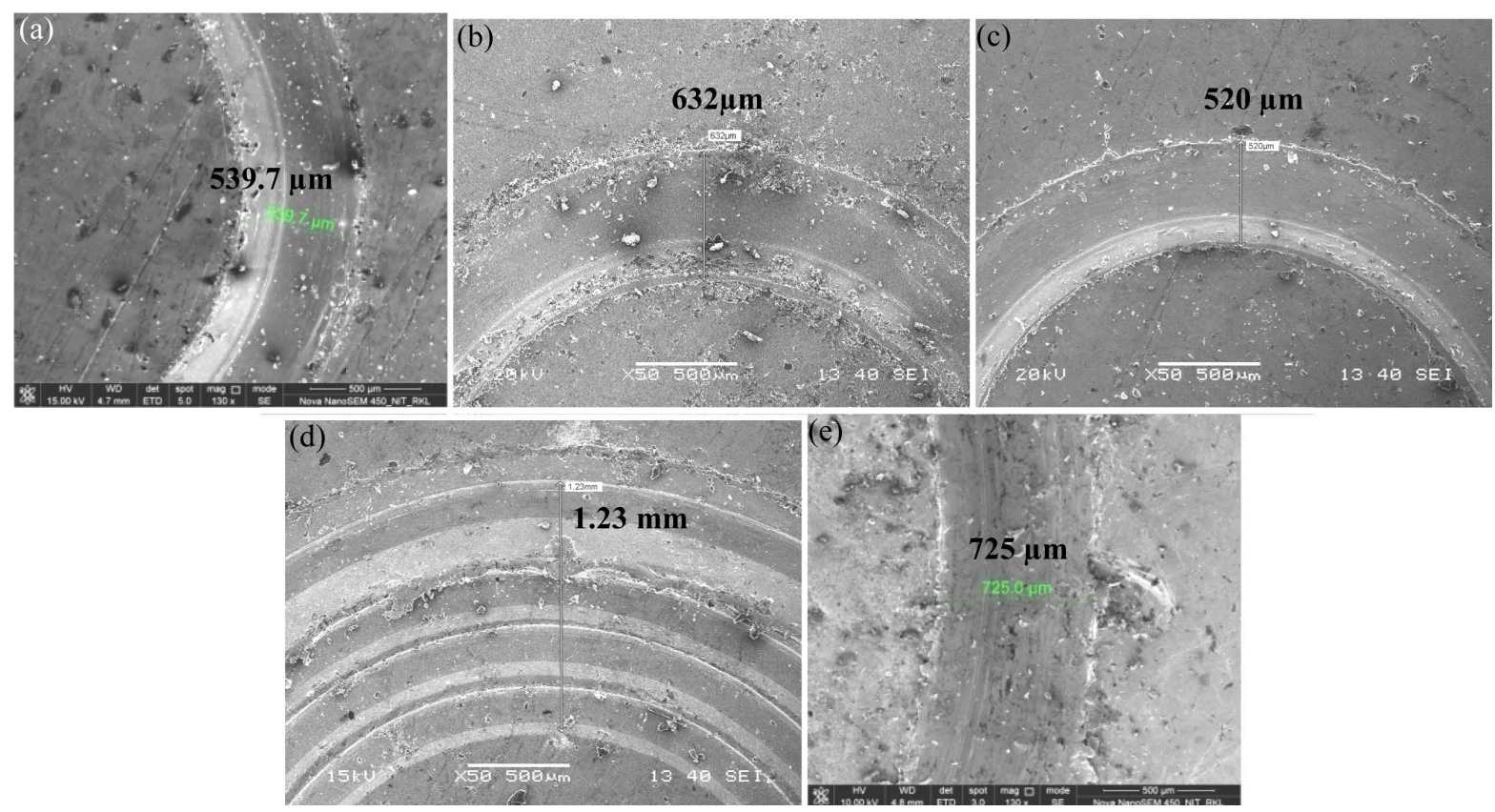

Figure 17. SEM images of wear tracks of (a) pure Cu; (b) Cu-1wt\% xGnP; (c) Cu-2wt\% xGnP; (d) Cu-3wt\% xGnP; and (e) Cu-5wt\% xGnP composites.

large amount of $\mathrm{xGnP}$ is added in the $\mathrm{Cu}-\mathrm{xGnP}$ composites. The width of the wear track was largest in the case $\mathrm{Cu}-3 \mathrm{wt} \% \mathrm{xGnP}$ and was found to be about $1.23 \mathrm{~mm}$. The SEM image in Figure 17(c) shows microfracture and wear debris in the wear track of $\mathrm{Cu}-3 \mathrm{wt} \% \mathrm{xGnP}$ composite. The surface of the wear track was found to be very rough. SEM observations in Figure 17(e) shows that there are some deep grooves and flake-like wear scars on the worn surface of the Cu-5 wt\% xGnP composites, which are typical characteristics of adhesive wear [42][44].

Figure 18 and Figure 19 show the SEM image and elemental maps of C, Cu and O of the wear tracks of Cu-1 wt $\%$ xGnP and of $\mathrm{Cu}-3 \mathrm{wt} \% \mathrm{xGnP}$ composites respectively. As the Cu-matrix gradually flaked during the wear test, the $\mathrm{xGnP}$ in the matrix near the surface were exposed. The $\mathrm{xGnP}$ became the working film on the worn surface. The worn contacting surfaces changed from the original metal surfaces into metals with lubricating graphite platelets. Due to the presence of the $\mathrm{xGnP}$ the adhesion between the composite and the counterpart significantly reduced and this subsequently led to lower wear depth. xGnP could be clearly seen in the wear tracks of both Cu-1 and 3 wt\% xGnP samples. The encircled region in the SEM images in Figure 18(a) and Figure 19(b) show the xGnP in the wear track. The elemental map of carbon in Figure 18(c) and Figure 19(c) shows the presence of only carbon in these regions confirming that they are $\mathrm{xGnP}$.

The XRD analysis of the wear debris from both $\mathrm{Cu}-2$ and $5 \mathrm{wt} \% \mathrm{xGnP}$ composites is shown in Figure 20. The XRD plot of the wear debris from the Cu-5 wt\% xGnP composite shows traces of xGnP in the wear debris. This suggests that both $\mathrm{Cu}$ and $\mathrm{xGnP}$ get worn out from the sample during the wear test. However, in the case of $\mathrm{Cu}-2 \mathrm{wt} \% \mathrm{xGnP}$ composite the peaks corresponding to $\mathrm{xGnP}$ is not seen. This is possibly due to the very low wt\% of $\mathrm{xGnP}$ in the wear debris of the sample.

The SEM images of the wear debris from the wear track of Cu-5 wt\% xGnP in Figure 21(a) and Figure 21(b) show plate like xGnP embedded in the $\mathrm{Cu}$ matrix. The XRD plot in Figure 20 also confirmed the presence of $\mathrm{xGnP}$ in the wear debris of Cu-5 wt\% xGnP composite. The elemental mapping of $\mathrm{Cu}, \mathrm{C}$ and $\mathrm{O}$ in the wear debris from Cu-5 wt\% xGnP composite in Figures 22(b)-(e) also confirms the presence of both Cu and xGnP. It can be clearly seen that the xGnP are embedded in the Cu matrix. Figure 22(a) is the SEM image of the region in the wear debris selected for the elemental mapping of $\mathrm{Cu}, \mathrm{C}, \mathrm{O}$ and $\mathrm{Cu}+\mathrm{C}+\mathrm{O}$. The elemental map of the wear debris also shows the presence of oxygen in the wear debris (refer Figure 22(d)). Oxygen is present both along with $\mathrm{Cu}$ and the $\mathrm{xGnP}$ in the wear debris. The heat generated during the dry sliding wear test causes the temperature of the specimen to rise resulting in the formation of an oxide film at the interface between the specimen and the diamond indenter of the wear tester. During the wear test $\mathrm{O}_{2}$ could be reduced to $\mathrm{O}^{-}$and $\mathrm{O}^{2-}$ and 

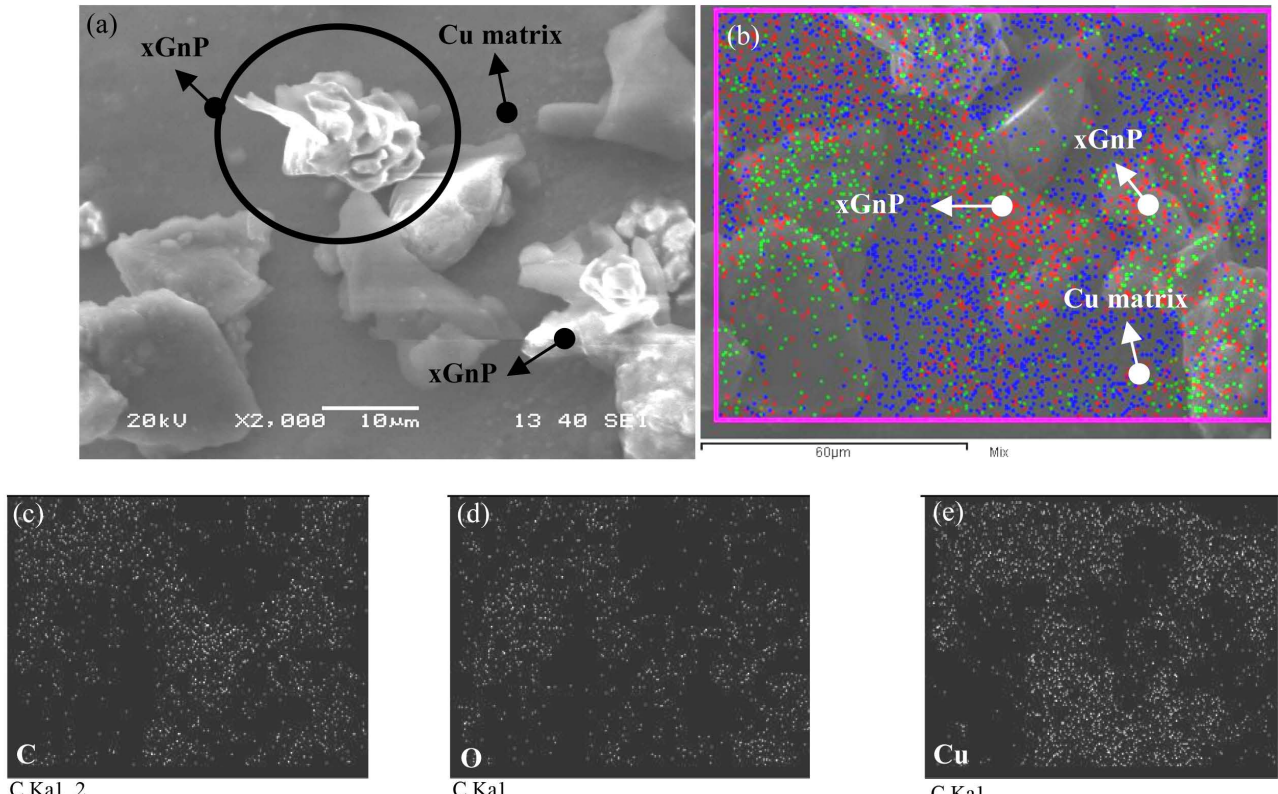

Figure 18. (a) SEM and elemental mapping of (b) $\mathrm{Cu}+\mathrm{C}+\mathrm{O}$; (c) $\mathrm{C}$; (d) $\mathrm{O}$; (e) $\mathrm{Cu}$ of the wear track of $\mathrm{Cu}-1$ wt\% xGnP composite.
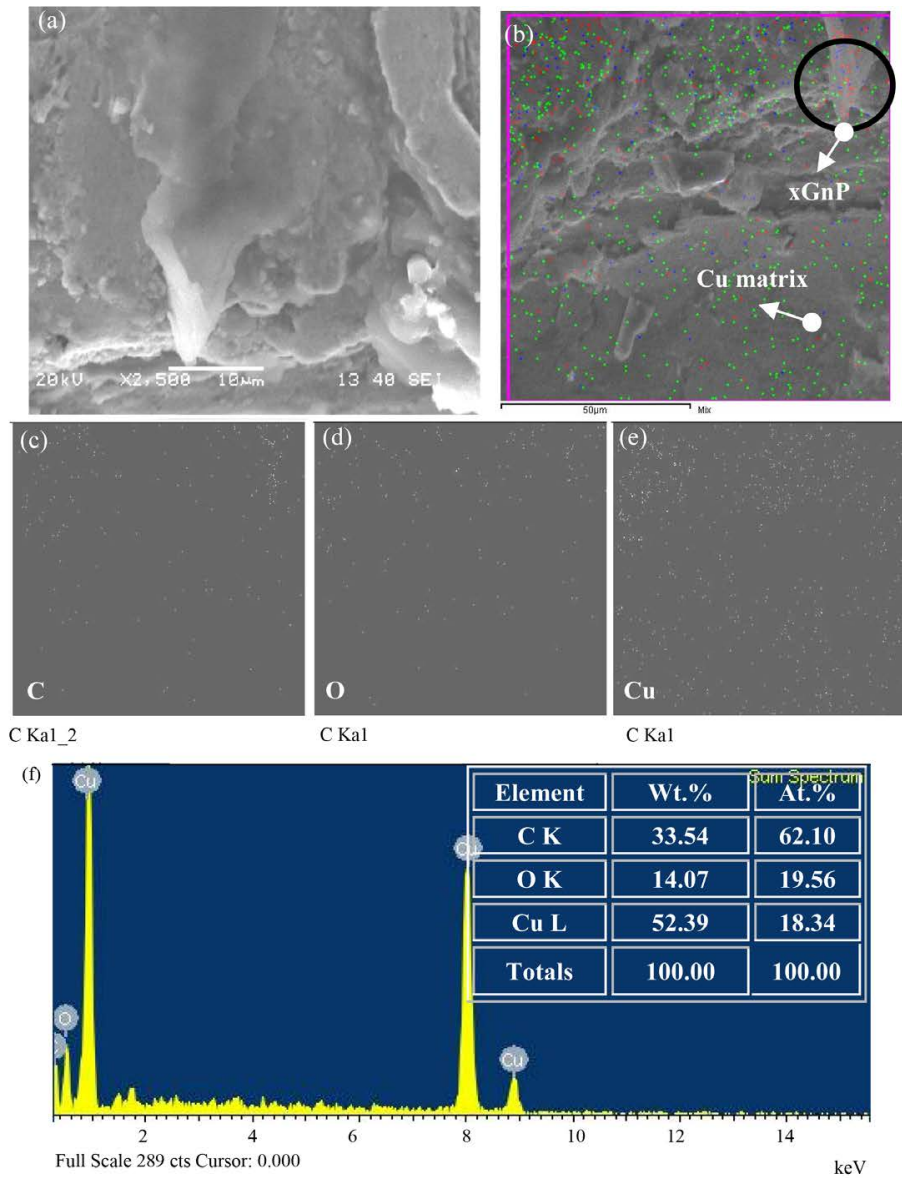

Figure 19. (a) SEM and elemental mapping of (b) $\mathrm{Cu}+\mathrm{C}+\mathrm{O}$; (c) $\mathrm{C}$; (d) $\mathrm{O}$; (e) $\mathrm{Cu}$ in the wear track of $\mathrm{Cu}-3 \mathrm{wt} \% \mathrm{xGnP}$ composite; (f) EDS analysis of the wear track of $\mathrm{Cu}-3 \mathrm{wt} \% \mathrm{xGnP}$ composite. 


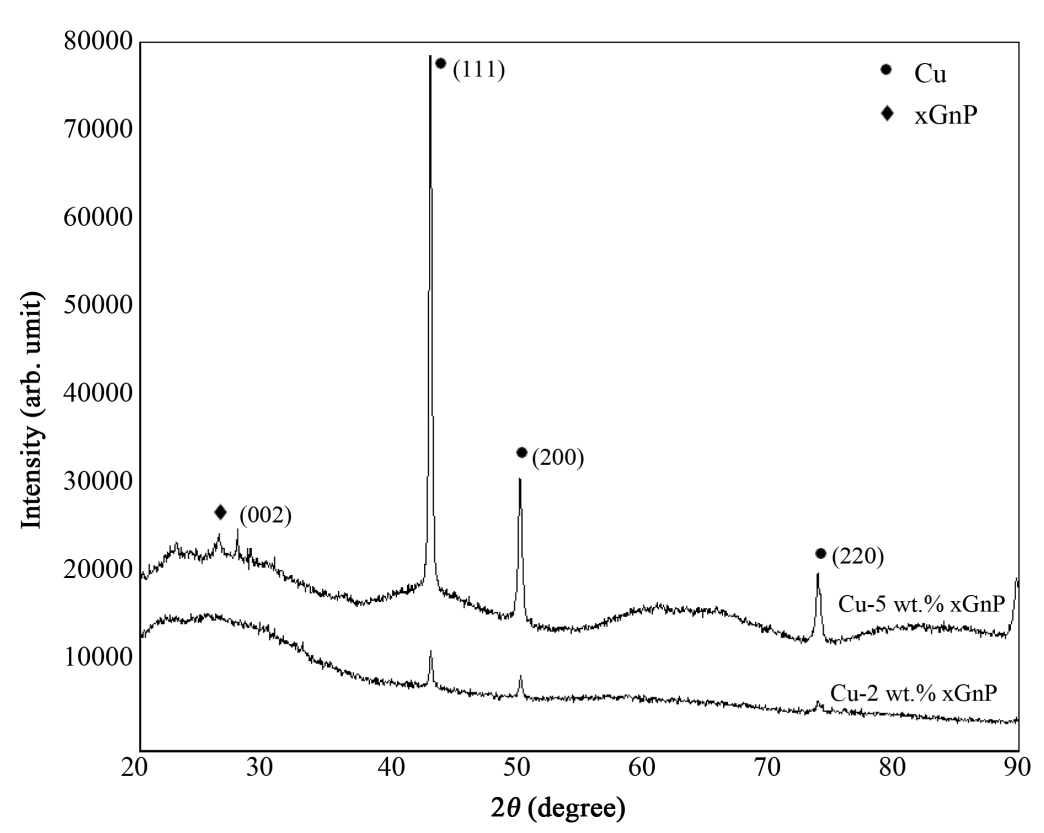

Figure 20. XRD of the wear debris from $\mathrm{Cu}-2$ and $5 \mathrm{wt} \% \mathrm{xGnP}$ composites.

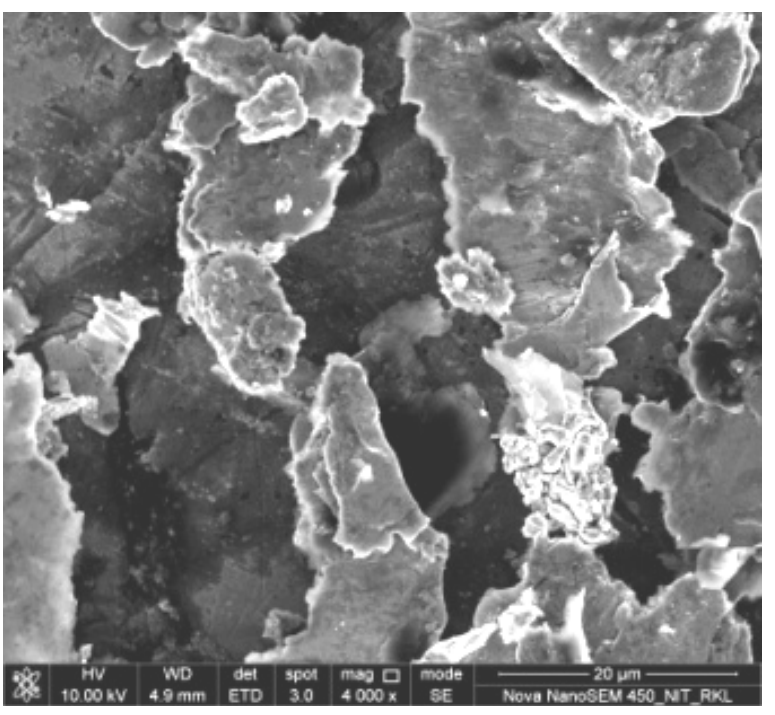

(a)

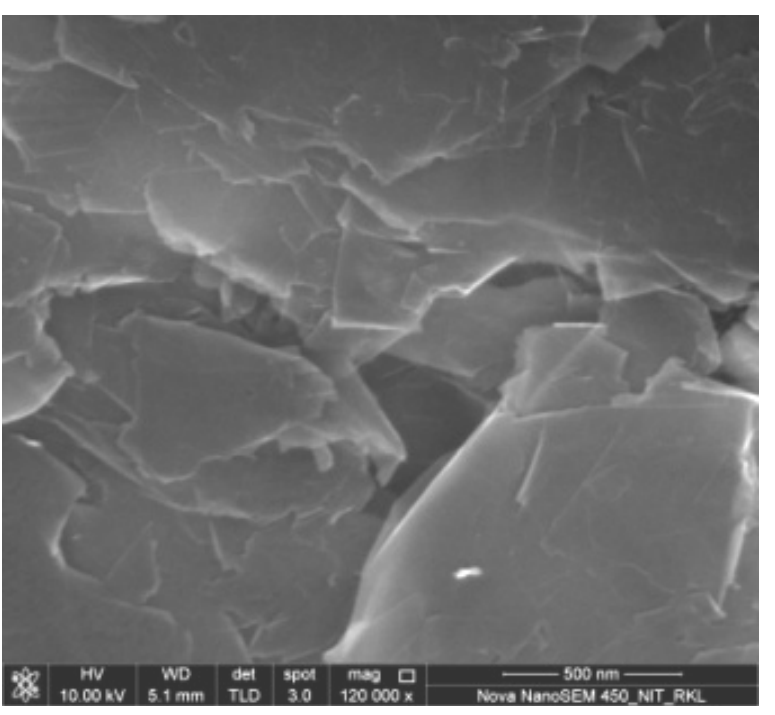

(b)

Figure 21. (a) \& (b) SEM of wear debris from the wear track of $\mathrm{Cu}-5 \mathrm{wt} \% \mathrm{xGnP}$ composite.

thereby oxidizing $\mathrm{Cu}$ to $\mathrm{Cu}^{+}$and $\mathrm{Cu}^{2+}$ forming a film of $\mathrm{Cu}_{2} \mathrm{O}$ or $\mathrm{CuO}$ on the surface. However, $\mathrm{O}^{-}$and $\mathrm{O}^{2-}$ could also react with the $\mathrm{xGnP}$ first instead of the $\mathrm{Cu}$ matrix as carbon is easier to oxidize compared to $\mathrm{Cu}$ resulting in the formation of $\mathrm{CO}$ and $\mathrm{CO}_{2}$. As a result the formation of $\mathrm{CuO}$ and $\mathrm{Cu}_{2} \mathrm{O}$ during the wear test was retarded. Thus the $\mathrm{xGnP}$ not only acts as a lubricant but it also prevents the $\mathrm{Cu}$ matrix from oxidizing. Due to this the weight loss of the composite is reduced [45] [46].

The fracture surfaces of the various samples of $\mathrm{Cu}-\mathrm{xGnP}$ composites fractured by tensile test were analyzed in SEM. The fracture behavior of both the monolithic $\mathrm{Cu}$ and the various $\mathrm{Cu}-\mathrm{xGnP}$ composites are shown in Figures 23(a)-(h). Dimples could be seen in the fracture surfaces of all the samples. Figure 23(a) and Figure 23(b) are the SEM images of the fracture surface of pure Cu. Figures 23(c)-(h) are the SEM images of the fracture surface of Cu-1, 2 and $3 \mathrm{wt} \% \mathrm{xGnP}$ nanocomposites respectively. It is clear from these SEM images that the nature of fracture is ductile in both pure $\mathrm{Cu}$ and the $\mathrm{Cu}-\mathrm{xGnP}$ composites. In the SEM images of $\mathrm{Cu}-1$ and $2 \mathrm{wt} \% \mathrm{xGnP}$ 


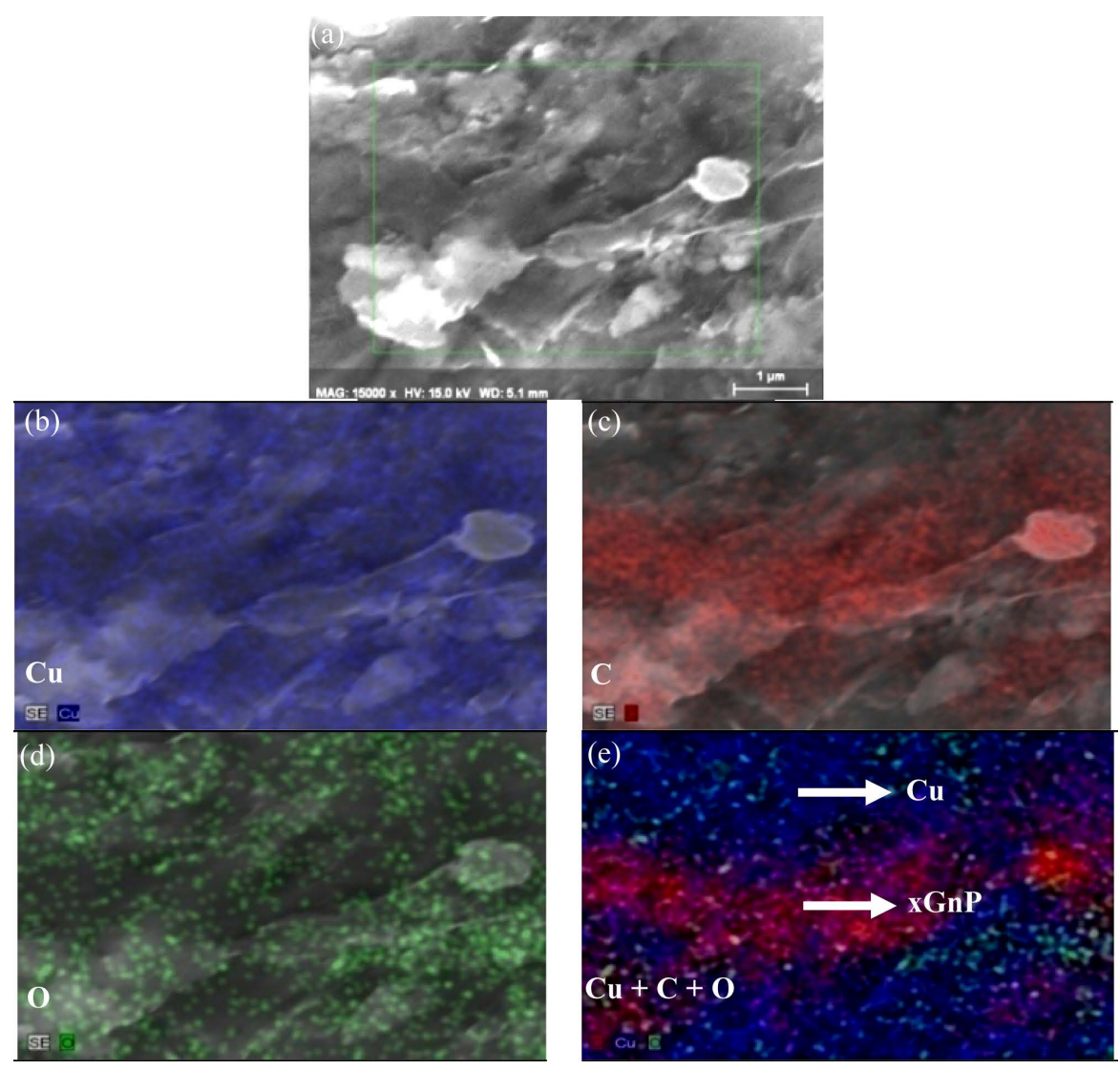

Figure 22. (a) SEM and elemental mapping of (a) $\mathrm{Cu}$; (b) $\mathrm{C}$; (c) $\mathrm{O}$; (d) $\mathrm{Cu}+\mathrm{C}+\mathrm{O}$ of the wear debris from $\mathrm{Cu}-5 \mathrm{wt} \% \mathrm{xGnP}$ composite.

nanocomposites $x G n P$ could be seen embedded in the Cu matrix. The SEM image in Figure 23(f) shows graphite nanoplatelets that have been pulled out form the $\mathrm{Cu}$ matrix during the tensile test. These graphite nanoplatelets also show bending at the edges as shown in the inset image in Figure 23(f). The SEM images of the fracture surfaces of all the composites also show the presence of dark pores. These pores were left behind during compaction and subsequent sintering and are responsible for the initiation of fracture. Pores are also seen where xGnPs are pulled out from the $\mathrm{Cu}$ matrix during the tensile test [35] [47] [48].

The elemental maps of $\mathrm{Cu}, \mathrm{C}$ and $\mathrm{O}$ in the fracture surface of $\mathrm{Cu}-1 \mathrm{wt} \% \mathrm{xGnP}$ sample were acquired in order to determine the distribution of these elements in the fracture surface of the sample. The elemental maps of $\mathrm{Cu}$, $\mathrm{C}$ and $\mathrm{O}$ in the fracture surface of $\mathrm{Cu}-1 \mathrm{wt} \% \mathrm{xGnP}$ sample are shown in Figures 24(b)-(d) respectively. From the elemental map of $\mathrm{C}$ in Figure 24(c) it is clear that the $\mathrm{xGnP}$ are embedded in the $\mathrm{Cu}$ matrix. The $\mathrm{xGnP}$ is also found to be uniformly distributed in the Cu matrix. The elemental maps of $\mathrm{C}$ in Figure 24(c) and $\mathrm{O}$ in Figure 24(d) are found to be very similar which is possibly due to the oxidation of the $\mathrm{xGnP}$.

\section{Conclusions}

In summary, $\mathrm{Cu}-\mathrm{xGnP}$ composites were developed via powder metallurgy route and the effect of the addition of $\mathrm{xGnP}$ to $\mathrm{Cu}$ matrix was determined.

1) Exfoliated graphite nanoplatelets (xGnP) were successfully synthesized by the ultrasonication of thermally exfoliated graphite. Raman spectroscopy analysis and HRTEM results confirm that the structural properties of the graphite nanoplatelets approach those of multilayer graphene. The exfoliation process was very effective.

2) The density of the $\mathrm{Cu}-\mathrm{xGnP}$ composites shows a decrease with the increase in the $\mathrm{xGnP}$ content due to the addition of $\mathrm{xGnP}$ which has a low density. However the relative density of the $\mathrm{Cu}-\mathrm{xGnP}$ increases with the increase in $\mathrm{xGnP}$ content. $\mathrm{xGnP}$ leads to a better sinterability and densification of the composite.

3) $\mathrm{Cu}-\mathrm{xGnP}$ nanocomposites fabricated by powder metallurgy route show an increase in hardness and wear 

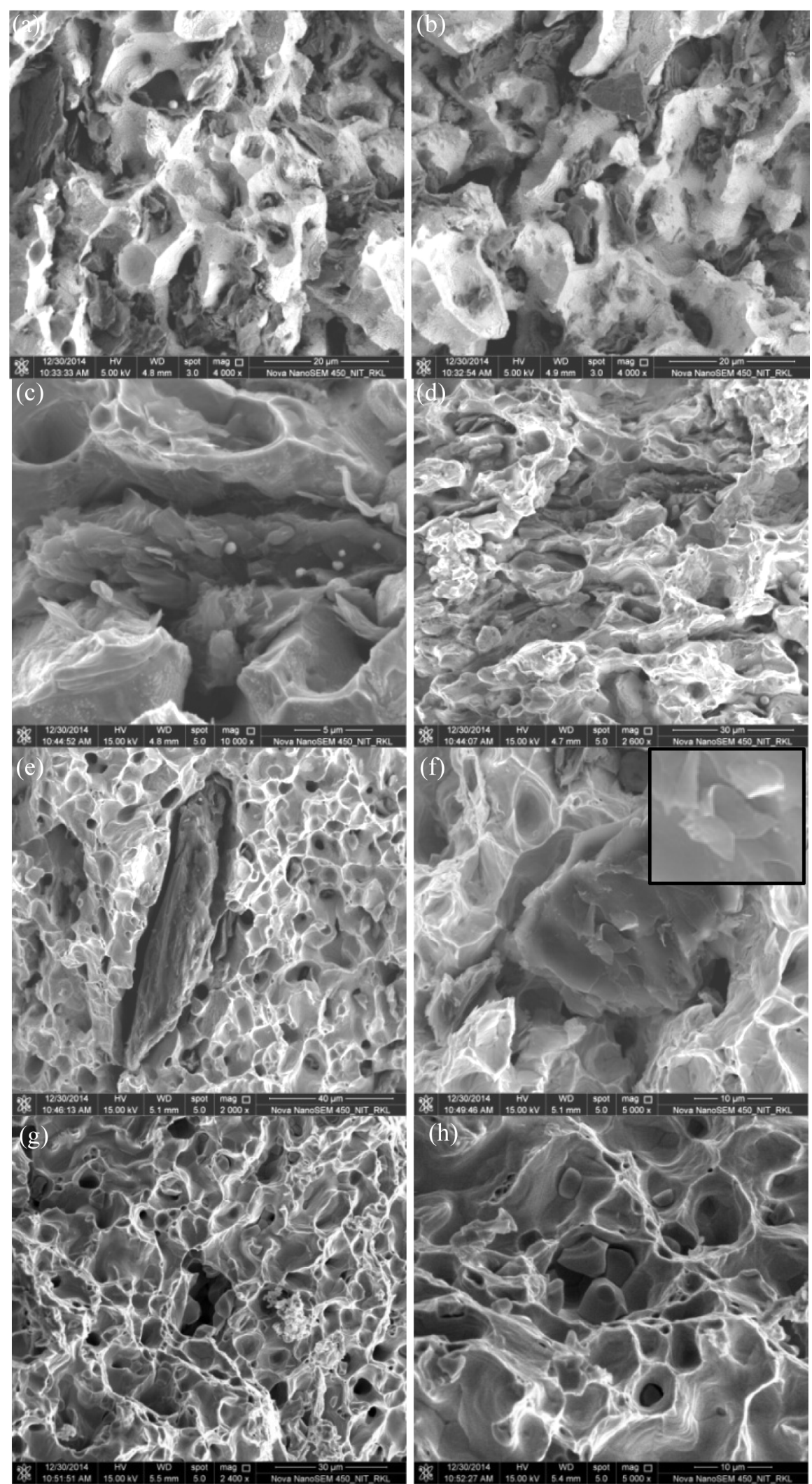

Figure 23. Fractographs of (a)-(b) Cu; (c)-(d) Cu-1 wt\% xGnP; (e)-(f) Cu-2 wt\% xGnP and (g)-(h) Cu-3 wt\% xGnP nanocomposites. 

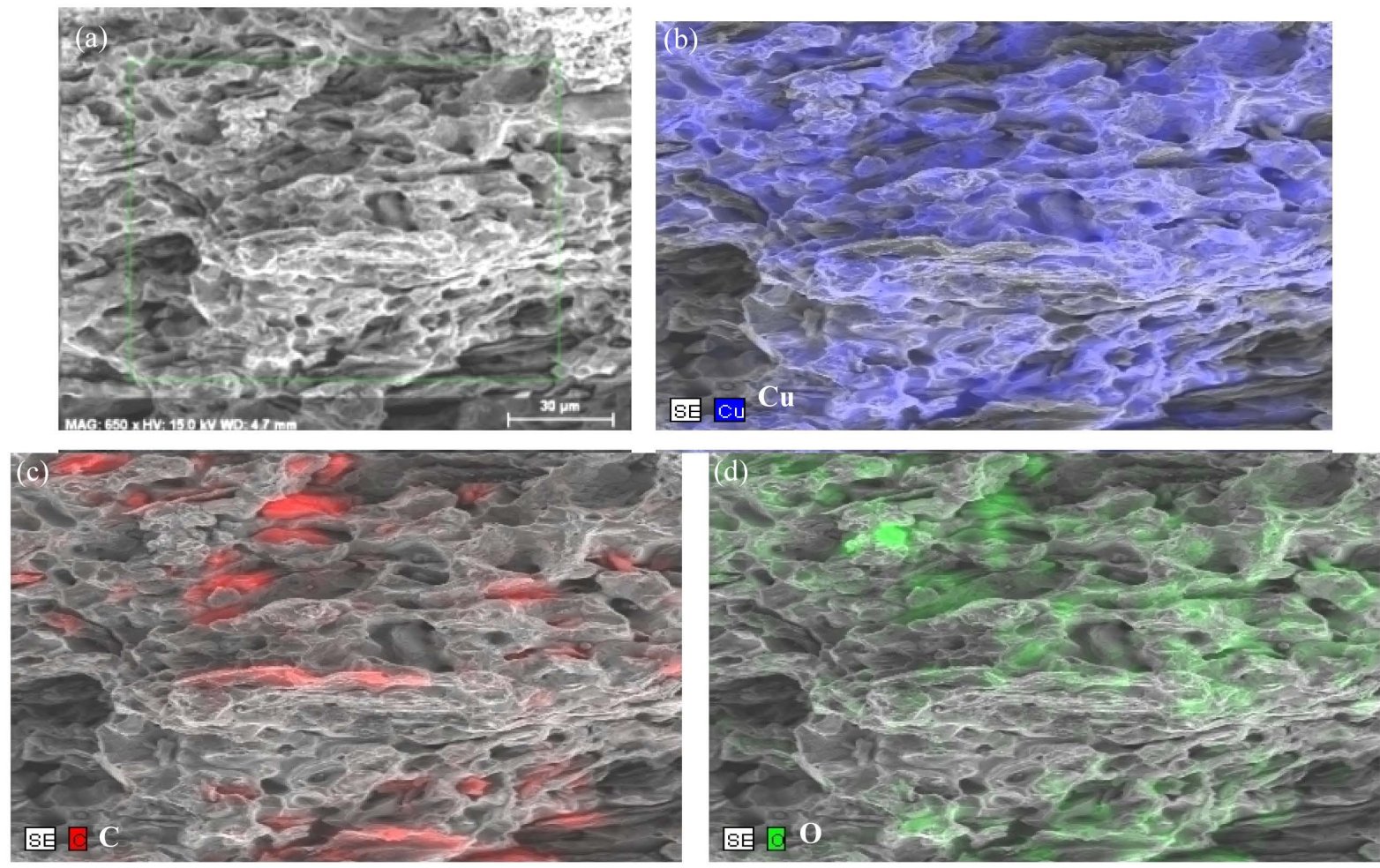

Figure 24. (a) SEM image of the fracture surface of $\mathrm{Cu}-1 \mathrm{wt} \% \mathrm{xGnP}$ sample. Elemental maps of (b) $\mathrm{Cu}$; (c) $\mathrm{C}$; and (d) $\mathrm{O}$ in the fractured surface of $\mathrm{Cu}-1 \mathrm{wt} \% \mathrm{xGnP}$ sample.

resistance upto $2 \mathrm{wt} \%$ addition of $\mathrm{xGnP}$. Beyond $2 \mathrm{wt} \%$ of $\mathrm{xGnP}$ there is a decrease in both the hardness and the wear resistance properties of the composites. Higher addition of $\mathrm{xGnP}$ leads to agglomeration of $\mathrm{xGnP}$ and this results in the decrease of both hardness and wear properties of the $\mathrm{Cu}-\mathrm{xGnP}$ composites.

4) The tensile strength and the strain to failure of the $\mathrm{Cu}-\mathrm{xGnP}$ composites also show a similar trend. Both the tensile strength and the strain to failure of the $\mathrm{Cu}-\mathrm{xGnP}$ composites increase upto the addition of $2 \mathrm{wt} \% \mathrm{xGnP}$. Addition of $\mathrm{xGnP}$ beyond $2 \mathrm{wt} \%$ leads to the decrease of the tensile strength of the composites due to the agglomeration of $\mathrm{xGnP}$.

5) The nature of fracture in pure $\mathrm{Cu}$ as well as the various $\mathrm{Cu}-\mathrm{xGnP}$ composites was found to be ductile. Nanoplatelets of graphite were found firmly embedded in the $\mathrm{Cu}$ matrix in the case of $\mathrm{Cu}$-xGnP composites containing low wt $\%$ of $x G n P$ which was responsible for the improvement of tensile strength, strain to failure, hardness and wear properties.

\section{Acknowledgements}

We gratefully acknowledge the support provided by the XRD, SEM and thermal analysis laboratories of Metallurgical and Materials Engineering Department and the FESEM laboratory of the Ceramic Engineering Department, NIT Rourkela. We also thank the support provided by Chemistry Department, NIT Rourkela and the Central Research Facility, IIT Kharagpur.

\section{References}

[1] Novoselov, K.S., Geim, A.K., Morozov, S.V., Jiang, D., Zhang, Y., Dubonos, S.V., Grigorieva, I.V. and Firsov, A.A. (2004) Electric Field Effect in Atomically Thin Carbon Films. Science, 306, 666-669. http://dx.doi.org/10.1126/science.1102896

[2] Geim, A.K. and Novoselov, K.S. (2007) The Rise of Graphene. Nature Materials, 6, 183-191. http://dx.doi.org/10.1038/nmat1849

[3] Wang, J., Li, Z., Fan, G., Pang, H., Chen, Z. and Zhang, D. (2012) Reinforcement with Graphene Nanosheets in Alu- 
minum Matrix Composites. Scripta Materialia, 66, 594-597. http://dx.doi.org/10.1016/j.scriptamat.2012.01.012

[4] Pavithra, C.L.P., Sarada, B.V., Rajulapati, K.V., Rao, T.N. and Sundararajan, G. (2014) A New Electrochemical Approach for the Synthesis of Copper-Graphene Nanocomposite Foils with High Hardness. Scientific Reports, 4, 4049. http://dx.doi.org/10.1038/srep04049

[5] Park, S. and Ruoff, R. (2009) Chemical Methods for the Production of Graphenes. Nature Nanotechnology, 4, $217-224$. http://dx.doi.org/10.1038/nnano.2009.58

[6] Liu, C., Zhang, H., Tang, Y. and Luo, S. (2014) Controllable Growth of Graphene/Cu Composite and Its Nanoarchitecture-Dependent Electrocatalytic Activity to Hydrazine Oxidation. Journal of Materials Chemistry A, 2, 4580-4587. http://dx.doi.org/10.1039/c3ta14137c

[7] Liu, W., Do, I., Fukushima, H. and Drzal, L.T. (2010) Influence of Processing on Morphology, Electrical Conductivity and Flexural Properties of Exfoliated Graphite Nanoplatelets-Polyamide Nanocomposites. Carbon Letters, 11, $279-284$. http://dx.doi.org/10.5714/CL.2010.11.4.279

[8] Chu, K. and Chang, C.J. (2014) Enhanced Strength in Bulk Graphene-Copper Composites. Physica Status Solidi (a), 211, 184-190. http://dx.doi.org/10.1002/pssa.201330051

[9] Wang, J., Li, Z., Fan, G., Pan, H., Chen, Z. and Zhang, D. (2012) Reinforcement with Graphene Nanosheets in Aluminum Matrix Composites. Scripta Materialia, 66, 594-597. http://dx.doi.org/10.1016/j.scriptamat.2012.01.012

[10] Nasibulin, A.G., Koltsova, T., Nasibulina, L.I., Anoshkin, I.V., Semencha, A., Tolochko, O.V. and Kauppinen, E.I. (2013) A Novel Approach for Composite Preparation by Direct Synthesis of Nanocarbons on Matrix or Filler Particles. Acta Materialia, 61, 1862-1871. http://dx.doi.org/10.1016/j.actamat.2012.12.007

[11] Koltsova, T.S., Nasibulina, L.I., Anoshkin, I.V., Mishin, V.V., Kauppinen, E.I., Tolochko, O.V. and Nasibulin, A.G. (2012) New Hybrid Copper Composite Materials Based on Carbon Nanostructures. Journal of Materials Science and Engineering B, 2, 240-246.

[12] Chung, D.D.L. (1987) Review: Exfoliation of Graphite. Journal of Materials Science, 22, 4190-4198.

[13] Drzal, L.T. and Fukushima, H. (2001) Graphite Nanoplatelets as Reinforcements for Polymers. Polymer Preprints, 42, 42-43.

[14] Kalaitzidou, K., Fukushima, H. and Drzal, L.T. (2007) Multifunctional Polypropylene Composites Produced by Incorporation of Exfoliated Graphite Nanoplatelets. Carbon, 45, 1446-1452. http://dx.doi.org/10.1016/j.carbon.2007.03.029

[15] Chen, G., Weng, W., Wu, D., Wu, C., Lu, J., Wang, P. and Chen, X. (2004) Preparation and Characterization of Graphite Nanosheets from Ultrasonic Powdering Technique. Carbon, 42, 753-759. http://dx.doi.org/10.1016/j.carbon.2003.12.074

[16] Afanasov, I.M., Shornikova, O.N., Kirilenko, D.A., Vlasov, I.I., Zhang, L., Verbeeck, J.V., Avdeev, V. and Tendeloo, G.V. (2010) Graphite Structural Transformations during Intercalation by $\mathrm{HNO}_{3}$ and Exfoliation. Carbon, 48, 18581865. http://dx.doi.org/10.1016/j.carbon.2010.01.055

[17] Yasmin, A., Luo, J.J. and Daniel, M.I. (2006) Processing of Expanded Graphite Reinforced Polymer Nanocomposites. Composites Science and Technology, 66, 1179-1186. http://dx.doi.org/10.1016/j.compscitech.2005.10.014

[18] Chen, G., Wu, D., Weng, W. and Wu, C. (2003) Exfoliation of Graphite Flake and Its Nanocomposites. Carbon, 41, 619-621. http://dx.doi.org/10.1016/S0008-6223(02)00409-8

[19] Viculis, L.M., Mack, J.J. and Kaner, R.B. (2003) A Chemical Route to Carbon Nanoscrolls. Science, $299,1361$. http://dx.doi.org/10.1126/science.1078842

[20] Carotenuto, G., Nicola, S.D., Palomba, M., Pullini, D., Horsewell, A., Hansen, T.W. and Nicolais, L. (2012) Mechanical Properties of Low-Density Polyethylene Filled by Graphite Nanoplatelets. Nanotechnology, 23, Article ID: 485705. http://dx.doi.org/10.1088/0957-4484/23/48/485705

[21] Cai, D. and Song, M. (2007) Preparation of Fully Exfoliated Graphite Oxide Nanoplatelets in Organic Solvents. Journal of Materials Chemistry, 17, 3678-3680. http://dx.doi.org/10.1039/b705906j

[22] Sahoo, S., Hatui, G., Bhattacharya, P., Dhibar, S. and Das, C.K. (2013) One Pot Synthesis of Graphene by Exfoliation of Graphite in ODCB. Graphene, 2, 42-48. http://dx.doi.org/10.4236/graphene.2013.21006

[23] Wang, J., Li, Z., Fan, G., Pang, H., Chen, Z. and Zhang, D. (2012) Reinforcement with Graphene Nanosheets in Aluminum Matrix Composites. Scripta Materialia, 66, 594-597. http://dx.doi.org/10.1016/j.scriptamat.2012.01.012

[24] Chu, K., Jia, C. and Li, W. (2012) Effective Thermal Conductivity of Graphene-Based Composites. Applied Physics Letters, 101, Article ID: 121916. http://dx.doi.org/10.1063/1.4754120

[25] Ciesielski, A. and Samori, P. (2014) Graphene via Sonication Assisted Liquid-Phase Exfoliation. Chemical Society Reviews, 43, 381-398. http://dx.doi.org/10.1039/C3CS60217F

[26] Zhao, W., Fang, M., Wu, F., Wu, H., Wang, L. and Chen, G. (2010) Preparation of Graphene by Exfoliation of Gra- 
phite Using Wet Ball Milling. Journal of Materials Chemistry, 20, 5817-5819.

http://dx.doi.org/10.1039/c0jm01354d

[27] Chandrasekaran, S., Seidel, C. and Schulte, K. (2013) Preparation and Characterization of Graphite Nano-Platelet (GNP)/Epoxy Nano-Composite: Mechanical, Electrical and Thermal Properties. European Polymer Journal, 49, 38783888. http://dx.doi.org/10.1016/j.eurpolymj.2013.10.008

[28] Sahoo, M., Antony, R.P., Mathews, T., Dash, S. and Tyagi, A.K. (2013) Raman Studies of Chemically and Thermally Reduced Graphene Oxide. The American Institute of Physics AIP Conference Proceedings, 1512, 1262-1263. http://dx.doi.org/10.1063/1.4791511

[29] Guo, H.L., Wang, X.F., Qian, Q.Y., Wang, F.B. and Xia, X.H. (2009) A Green Approach to the Synthesis of Graphene Nanosheets. ACS Nano, 3, 2653-2659. http://dx.doi.org/10.1021/nn900227d

[30] Zhang, S.T., Gu, A.Y., Gao, H.F. and Che, X.Q. (2011) Characterization of Exfoliated Graphite Prepared with the Method of Secondary Intervening. International Journal of Industrial Chemistry, 2, 123-130.

[31] Tang, Y., Yang, X., Wang, R. and Li, M. (2014) Enhancement of the Mechanical Properties of Graphene-Copper Composites with Graphene-Nickel Hybrids. Materials Science \& Engineering A, 599, 247-254. http://dx.doi.org/10.1016/j.msea.2014.01.061

[32] Kim, W.J., Lee, T.J. and Han, S.H. (2014) Multi-Layer Graphene/Copper Composites: Preparation Using High-Ratio Differential Speed Rolling, Microstructure and Mechanical Properties. Carbon, 69, 55-65. http://dx.doi.org/10.1016/j.carbon.2013.11.058

[33] Yoo, S.J., Han, S.H. and Kim, W.J. (2013) A Combination of Ball Milling and High-Ratio Differential Speed Rolling for Synthesizing Carbon Nanotube/Copper Composites. Carbon, 61, 487-500. http://dx.doi.org/10.1016/j.carbon.2013.04.105

[34] Subramanian, P.R. and Laughlin, D.E. (1994) Phase Diagrams of Binary Copper Alloys, Monograph Series on Alloy Phase Diagrams. Volume 10, ASM International, Materials Park, 109.

[35] Kim, Y., Lee, J., Yeom, M.S., Shin, J.W., Kim, H., Cui, Y., Kysar, J.W., Hone, J., Jung, Y., Jeon, S. and Han, S.M. (2013) Strengthening Effect of Single-Atomic-Layer Graphene in Metal-Graphene Nanolayered Composites. Nature Communications, 4, 2114. http://dx.doi.org/10.1038/ncomms3114

[36] Bhardwaj, N., Manjula, K.S., Srinivasulu, B. and Subhas, S.C. (2012) Synthesis and Characterization of Exfoliated Graphite/ABS Composites. Open Journal of Organic, Polymer Materials, 2, 74-78.

[37] Porwal, H., Tatarko, P., Saggar, R., Grasso, S., Manid, M.K., Dlouhý, I., Duszae, J. and Reece, M.J. (2014) Tribological Properties of Silica-Graphene Nano-Platelet Composites. Ceramics International, 40, 12067-12074. http://dx.doi.org/10.1016/j.ceramint.2014.04.046

[38] Bartolucci, S.F., Paras, J., Rafiee, M.A., Rafiee, J., Lee, S., Kapoor, D. and Koratkar, N. (2011) Graphene-Aluminum Composites. Materials Science and Engineering: A, 528, 7933-7937. http://dx.doi.org/10.1016/j.msea.2011.07.043

[39] Hwang, J., Yoon, T., Jin, S.H., Lee, J., Kim, T.S., Hong, S.H. and Jeon, S. (2013) Enhanced Mechanical Properties of Graphene/Copper Nanocomposites Using a Molecular-Level Mixing Process. Advanced Materials, 25, 6724-6729. http://dx.doi.org/10.1002/adma.201302495

[40] Ovid'ko, I.A. (2014) Metal-Graphene Nanocomposites with Enhanced Mechanical Properties: A Review. Reviews on Advanced Materials Science, 38, 190-200.

[41] Ashraf, A.A. (2008) Wear Characteristic of Exfoliated Graphite Nano Sheets/Copper Metal Matrix Composite. Proceedings of the Sixth International Scientific Conference on Mechanics.

[42] Wang, L., Cui, Y., Yang, S., Li, B., Liu, Y., Dong. P., Bellah, J., Fan, G., Vajtai, R. and Fei, W. (2015) Microstructure and Properties of Carbon Nanosheet/Copper Composites Processed by Particle-Assisted Shear Exfoliation. RSC Advances, 5, 19321-19328. http://dx.doi.org/10.1039/C4RA14255A

[43] Latief, F.H., Sherif, E.M., Almajid, A.A. and Junaedi, H. (2011) Fabrication of Exfoliated Graphite Nanoplatelets-Reinforced Aluminum Composites and Evaluating Their Mechanical Properties and Corrosion Behavior. Journal of Analytical and Applied Pyrolysis, 92, 485-492. http://dx.doi.org/10.1016/j.jaap.2011.09.003

[44] Rafiee, M.A., Rafiee, J., Wang, Z., Song, H., Yu, Z.Z. and Koratkar, N. (2009) Enhanced Mechanical Properties of Nanocomposites at Low Graphene Content. ACS Nano, 3, 3884-3890. http://dx.doi.org/10.1021/nn9010472

[45] John, M. (1980) Corrosion and Oxidation. Ellis Horwood Limited, Halsted Press, New York, 161-194.

[46] Dong, S.R., Tu, J.P. and Zhang, X.B. (2001) An Investigation of the Sliding Wear Behavior of Cu-Matrix Composite Reinforced by Carbon Nanotubes. Materials Science and Engineering: A, 313, 83-87. http://dx.doi.org/10.1016/S0921-5093(01)00963-7

[47] Rashad, M., Pan, F., Tang, A. and Asif, M. (2014) Effect of Graphene Nanoplatelets Addition on Mechanical Properties of Pure Aluminum Using a Semi-Powder Method. Progress in Natural Science: Materials International, 24, 
101-108. http://dx.doi.org/10.1016/j.pnsc.2014.03.012

[48] King, J.A., Via, M.D., Mills, O.P., Alpers, D.S., Sutherland, J.W. and Bogucki, G.R. (2011) Effects of Multiple Carbon Fillers on the Electrical and Thermal Conductivity and Tensile and Flexural Modulus of Polycarbonate-Based Resins. Journal of Composite Materials, 46, 331-350.

http://dx.doi.org/10.1177/0021998311422750 